\title{
Integration of NMR and NMRC in the Investigation of the Pore Size Distribution of Tight Sandstone Reservoirs: A Case Study in the Upper Paleozoic of Dongpu Depression
}

\author{
Ning Zhu $\mathbb{D}^{1},{ }^{1}$ Suping Yao $\mathbb{D}^{1},{ }^{1}$ Xuejun Wang, ${ }^{2}$ Binfeng Xia, ${ }^{2}$ and Yunxian Zhang ${ }^{2}$ \\ ${ }^{1}$ State Key Laboratory of Surficial Geochemistry, School of Earth Sciences and Engineering, Nanjing University, Nanjing, \\ Jiangsu 210023, China \\ ${ }^{2}$ Research Institute of Petroleum Exploration and Production, Zhongyuan Oil Field, SINOPEC, Puyang, Henan 457001, China \\ Correspondence should be addressed to Suping Yao; spyao@nju.edu.cn
}

Received 25 June 2021; Revised 15 August 2021; Accepted 1 October 2021; Published 20 October 2021

Academic Editor: Zhaojie Song

Copyright (c) 2021 Ning Zhu et al. This is an open access article distributed under the Creative Commons Attribution License, which permits unrestricted use, distribution, and reproduction in any medium, provided the original work is properly cited.

\begin{abstract}
Exploring appropriate methods to understanding the pore structure and overall pore size distribution (PSD) of tight sandstone reservoir is important for evaluating the quality of the reservoir. An integration analysis comprising X-ray diffraction (XRD), three beams of argon ion (TIB) polishing approach, scanning electron microscopy (SEM), high-pressure mercury intrusion (HPMI), nuclear magnetic resonance (NMR), and nuclear magnetic resonance cryoporometry (NMRC) was applied to determine the pore structure of the tight sandstone reservoirs in the Upper Paleozoic of Dongpu Depression as well as their relationship with the physical properties of the reservoirs. NMRC offered the possibility to obtain the nanoscale $(4-1400 \mathrm{~nm})$ pore structure of the reservoirs directly and accurately. Therefore, an attempt by combining NMRC and NMR can reveal the PSD of tight sandstone reservoirs with different pore structures. The results showed that the tight sandstone reservoirs consisted of intergranular, intragranular, and intercrystalline (clay mineral) pores. The full PSD intelligibly showed pore structure characteristics of four different types of reservoirs, with pore sizes ranging from $2 \mathrm{~nm}$ to dozens of microns. Specifically, the overall PSD of type I reservoirs showed a broad unimodal distribution pattern with the peaks in the range $0.1-2 \mu \mathrm{m}$, indicating an association with dissolution intergranular pores, and for type II reservoirs, the overall PSD showed a bimodal distribution pattern, with their left and right peaks, in the ranges $0.004-0.01 \mu \mathrm{m}$ and $0.15-0.4 \mu \mathrm{m}$, respectively, showing similar amplitudes, implying the predominance of both intergranular (mesopores) and intergranular (macropores) pores. The full PSDs of type III and IV reservoirs showed much lower amplitudes than type I and II reservoirs, indicating a lower pore number and a complex pore structure. Furthermore, NMRC also demonstrated that different diagenesis resulted in a correlation between pore structure and reservoir physical properties.
\end{abstract}

\section{Introduction}

Tight oil and gas reservoirs, as one of the unconventional natural resources, are becoming important alternative oil and gas resources in the twenty-first century and account for an increasing proportion of the total number of oil and gas resources on a global scale $[1,2]$. Compared with conventional oil and gas resources, they are characterized by poor stability, strong heterogeneity, and a complex oilwater interaction mechanism, and are also very difficult to evaluate and explore [3]. Additionally, tight sandstone reservoirs represent one of the important tight oil and gas resources, and a clear understanding of their pore structure is the basis for the study of tight oil and gas accumulation, the associated charging mechanism, and the resource potential [4-7]. However, their strong heterogeneity as well as their substantial number of nanoscale pore throats make the characterization of their pore structure difficult $[8,9]$. It has also been demonstrated that nanoscale space accounts for approximately $70-80 \%$ of the total volume of the 

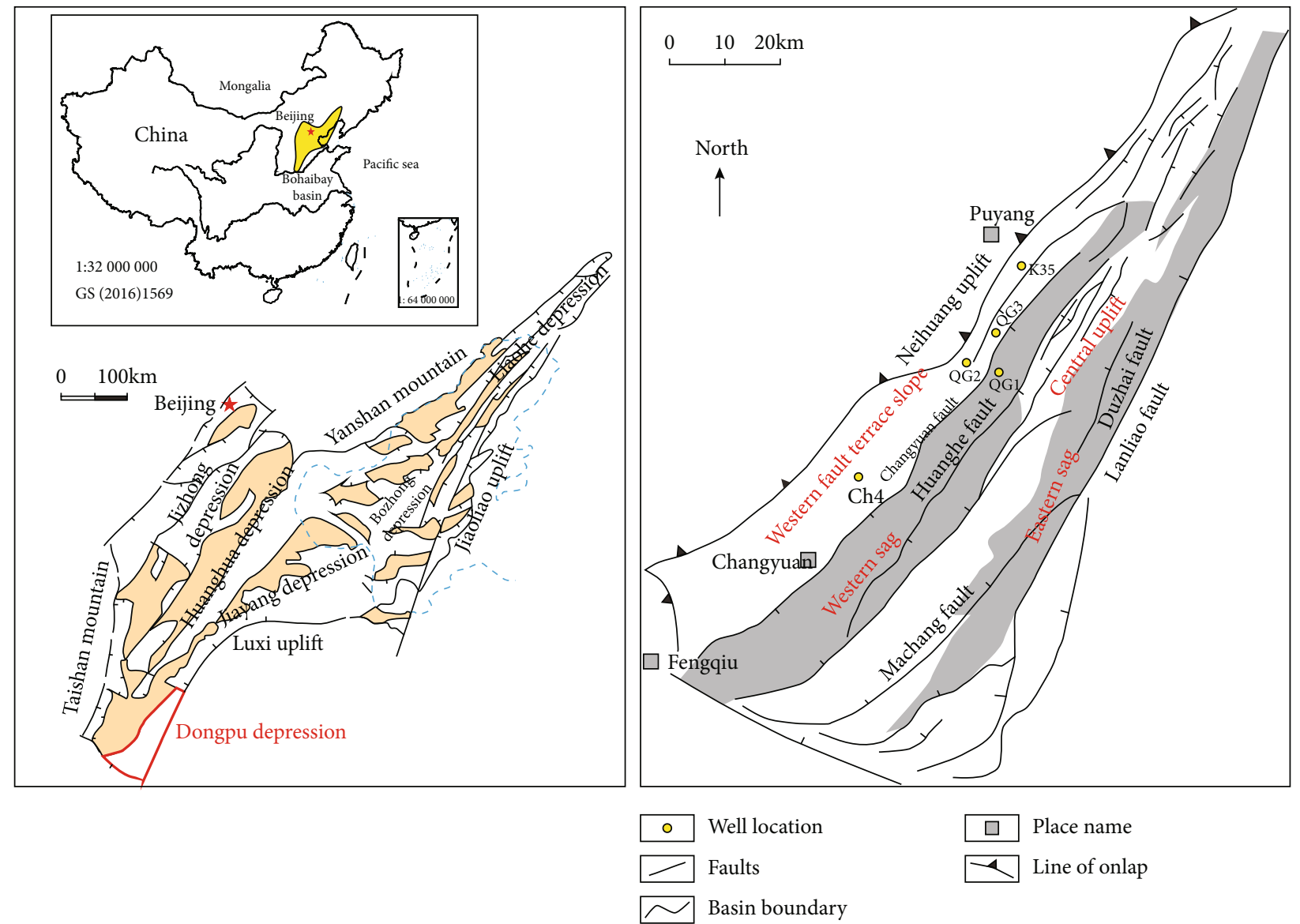

Figure 1: Location of study area and the distribution of core wells.

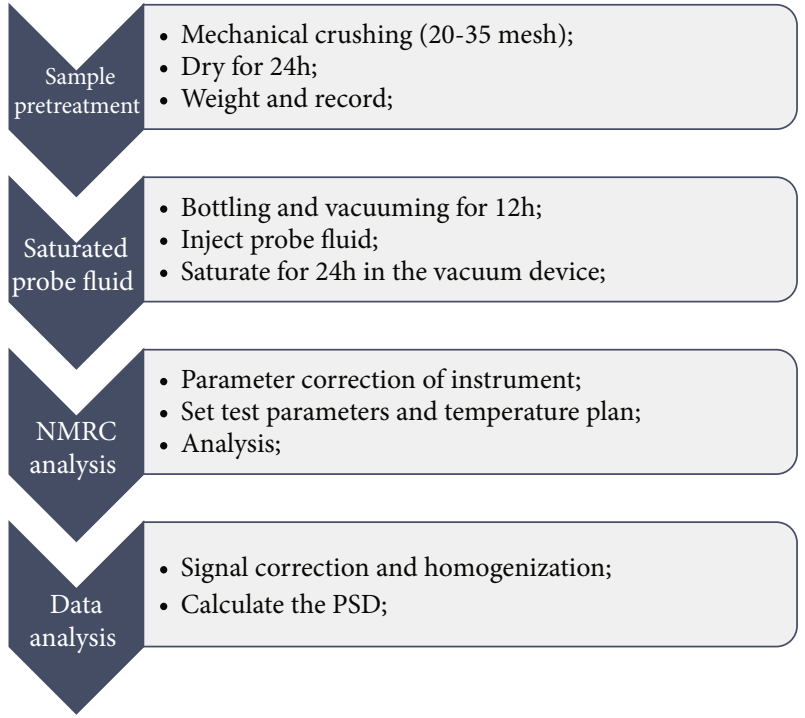

FIGURE 2: Method system for characterizing PSD of tight sandstone by NMRC.

reservoir space, and their main pore size distribution (PSD) is $40-700 \mathrm{~nm}[10,11]$. Further, it has also been reported that the distribution and sizes of the pores in tight sandstone reservoirs determine their physical properties; thus, they signif- icantly affect oil and gas recovery. Therefore, research on pore structure is of great significance to tight oil and gas resource exploration.

Presently, several techniques are used in pore characterization and quantitative research. For example, casting thin sections (CTS) and scanning electron microscopy (SEM) have been employed to observe the pore morphology of tight sandstone reservoirs [12-14]. Additionally, high pressure mercury intrusion (HPMI), constant-rate mercury intrusion (CRMI), low-temperature nitrogen gas adsorption $\left(\mathrm{N}_{2} \mathrm{GA}\right)$, and nuclear magnetic resonance (NMR) have also been utilized to perform quantitative studies on pore number, size, and distribution [15-19]. However, even though these different methods have certain advantages, they each have their limitations. Particularly, CTS and SEM are intuitive, but do not offer the possibility to obtain reliable quantitative data [20, 21]. Further, HPMI is advantageous with respect to the characterization of micron-scale pores; however, it may lead to the destruction of the pore structure under a higher capillary pressure, especially at the nanometer scale, resulting in an experimental accuracy that is far lower than the theoretical testing accuracy [22-24]. In the HPMI experiment, PSD characteristics between approximately $3 \mathrm{~nm}$ and $63 \mu \mathrm{m}$ could be obtained based on the experimental conditions. However, pores with diameter larger than $10 \mu \mathrm{m}$ or less than $0.01 \mu \mathrm{m}$ were difficult to detect accurately owing 
TABLE 1: Sample number and mineral composition of sandstone samples.

\begin{tabular}{|c|c|c|c|c|c|c|c|c|c|}
\hline \multirow{2}{*}{ Sample ID } & \multirow{2}{*}{ Well ID } & \multirow{2}{*}{ Depth (m) } & \multicolumn{7}{|c|}{ Whole rock X-ray diffraction analysis } \\
\hline & & & Quartz (\%) & Feldspar (\%) & Calcite (\%) & Siderite (\%) & Halite (\%) & Pyrite $(\%)$ & Clay $(\%)$ \\
\hline 1 & Q2 & 3460.60 & 78.7 & 17.8 & 0.0 & 0.0 & 0.0 & 0.6 & 2.9 \\
\hline 2 & Q3 & 3583.88 & 67.7 & 23.8 & 1.4 & 0.0 & 0.0 & 1.3 & 5.8 \\
\hline 3 & Q2 & 3584.62 & 66.8 & 24.6 & 0.6 & 0.0 & 0.0 & 1.1 & 6.9 \\
\hline 4 & Q2 & 3585.61 & 68.4 & 27.1 & 0.0 & 0.0 & 0.0 & 0.0 & 4.5 \\
\hline 5 & Q3 & 3586.16 & 64.1 & 29.1 & 0.7 & 0 & 0 & 0.8 & 5.3 \\
\hline 6 & Q3 & 4112.9 & 68.8 & 7.2 & 0.8 & 0.0 & 0.0 & 0.0 & 11.6 \\
\hline 7 & Q3 & 4113.69 & 62.8 & 11.1 & 0.4 & 2.8 & 1.2 & 0.0 & 21.7 \\
\hline 8 & Q3 & 3586.5 & 63.8 & 34.8 & 0 & 0 & 0 & 0 & 1.4 \\
\hline 9 & Q3 & 4059.35 & 68.8 & 6.7 & 1.6 & 4.7 & 0.0 & 0.0 & 18.2 \\
\hline 10 & Q3 & 4112.45 & 70.5 & 8.2 & 0.0 & 0.0 & 0.8 & 0.0 & 20.5 \\
\hline 11 & Q3 & 4059.48 & 68.5 & 6.4 & 1.1 & 4.8 & 0.0 & 0.0 & 19.2 \\
\hline 12 & Q2 & 4053.26 & 65.2 & 6.1 & 1.0 & 0.9 & 0.0 & 0.0 & 26.8 \\
\hline
\end{tabular}

TABLE 2: Petrophysical parameters and results of FESEM image extracted by PCAS.

\begin{tabular}{|c|c|c|c|c|c|c|c|}
\hline Sample & $\begin{array}{c}\text { Reservoir } \\
\text { types }\end{array}$ & $\begin{array}{c}\text { Helium porosity } \\
(\%)\end{array}$ & $\begin{array}{c}\text { Gas permeability } \\
(\mathrm{mD})\end{array}$ & $\begin{array}{c}\text { Region percentage } \\
(\%)\end{array}$ & $\begin{array}{c}\text { Pore numbers/ } \\
\mathrm{mm}^{2}\end{array}$ & $\begin{array}{l}\text { Average form } \\
\text { factor }\end{array}$ & $\begin{array}{c}\text { Probability } \\
\text { entropy }\end{array}$ \\
\hline 1 & Type I & 7.21 & 0.0997 & 7.62 & 2652 & 0.5812 & 0.7384 \\
\hline 2 & Type I & 8.85 & 0.409 & 8.56 & 3089 & 0.6147 & 0.7926 \\
\hline 3 & Type I & 7.81 & 0.332 & I & I & I & I \\
\hline 4 & Type I & 7.63 & 0.188 & I & I & I & I \\
\hline 6 & Type II & 5.93 & 0.0803 & I & I & l & I \\
\hline 7 & Type II & 4.29 & 0.0601 & 5.03 & 3681 & 0.5093 & 0.8813 \\
\hline 10 & Type II & 6.19 & 0.043 & 7.49 & 4174 & 0.4855 & 0.8601 \\
\hline 8 & Type III & 3.72 & 0.0479 & 2.08 & 1725 & 0.5122 & 0.9904 \\
\hline 5 & Type III & 4.36 & 0.0426 & I & I & I & I \\
\hline 9 & Type IV & 3.16 & 0.0438 & I & I & 1 & I \\
\hline 11 & Type IV & 2.13 & 0.0309 & 0.46 & 472 & 0.4537 & 0.9913 \\
\hline 12 & Type IV & 2.63 & 0.0245 & 0.82 & 589 & 0.4662 & 0.9885 \\
\hline
\end{tabular}

to shielding effects [3]. Furthermore, CRMI may overcome the setbacks associated with a high pressure; however, it is limited by the maximum pressure that results when the pore size is below $120 \mathrm{~nm}[24,25]$, and reportedly, $\mathrm{N}_{2} \mathrm{GA}$ does not offer the possibility to detect pore sizes that exceed $200 \mathrm{~nm}$; thus, it is unsuitable for the characterization of tight sandstone reservoirs [18]. It has also been observed that NMR only offers the possibility to reflect the approximate outline and range of the PSD, but cannot accurately reflect the pore size changes within a small range $[4,26]$. It was possible to measure the PSD between approximately $1 \mathrm{~nm}$ and $100 \mu \mathrm{m}$; however, the measurement was limited by the accuracy of the method, which could not effectively display the PSD characteristics of the different types of reservoirs.

As an emerging pore characterization technology, nuclear magnetic resonance cryoporometry (NMRC) does not only cover the measurement range of nanopores and realize the continuous characterization of a given sample but also allows the direct and efficient acquisition of information, such as PSD and porosity [13, 20, 27, 28]. Unlike
NMR, the theoretical basis of NMRC is the GibbsThomson equation, which offers the possibility to directly obtain pore size data based on changes in the melting point of a solid [29]. In an attempt to use this method to measure rock pore sizes, some scholars have used octamethylcyclotetrasiloxane (OMCTS) as the probe liquid, which does not only improve the accuracy of mesopore and macropore measurements but also meet the testing requirements for tight sandstone reservoir (between 4 and $1400 \mathrm{~nm}$ ) characterization $[13,28]$. However, it greatly narrowed down the measurement range and cannot truly and comprehensively display the pore size distribution of the sample.

In this study, we collected tight sandstone samples from the Upper Paleozoic of Dongpu Depression to conduct an integrated research, comprising XRD, FESEM-PCAS, HPMI, NMR, and NMRC. We attempted to reveal their full PSD by combining NMRC and NMR and characterized different types of pore structures in the reservoir from both qualitatively and quantitatively. After that, we discussed the possible diagenesis processes that form these pore structures 


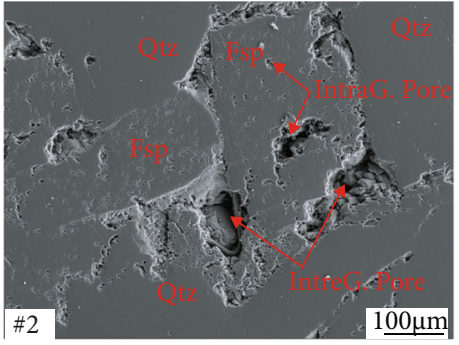

(a)

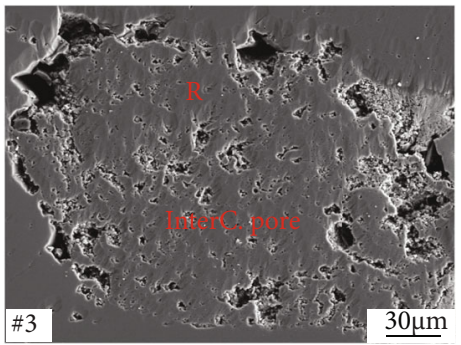

(d)

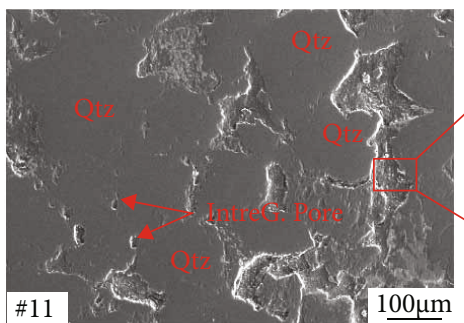

(g)

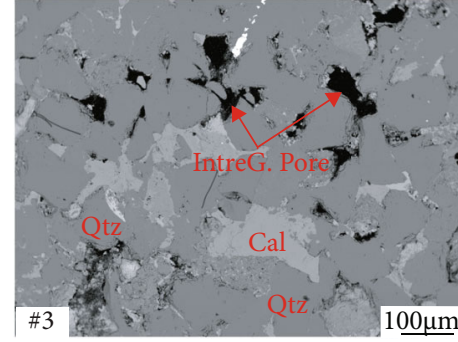

(b)

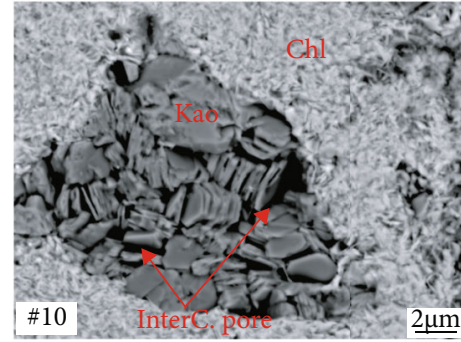

(e)

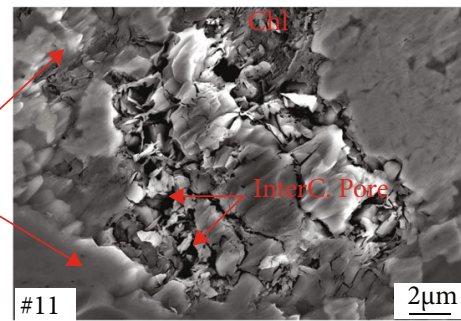

(h)

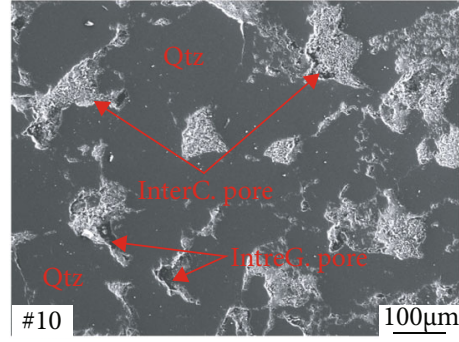

(c)

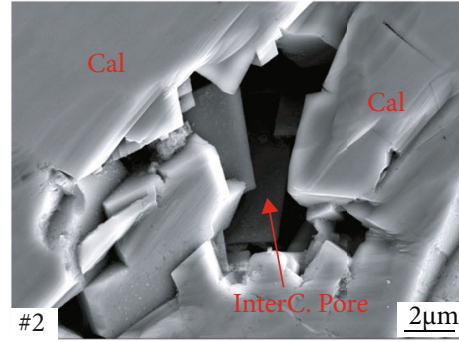

(f)

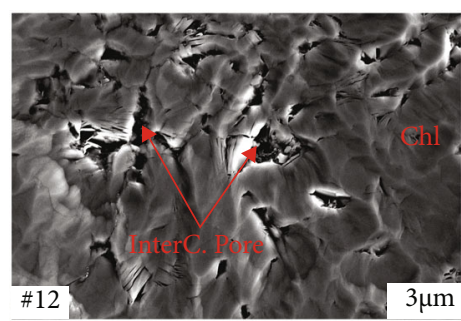

(i)

FIgURE 3: Typical pore types in sandstone samples obtained via SEM imagery. Fsp: feldspar; Qtz: quartz; Cal: calcite; R: rock debris; Chl: chlorite; Kao: kaolinite; InterG. Pore: intergranular pore; IntraG. Pore: intragranular pore; InterC. Pore: intercrystalline pore.

and the intrinsic relationships between pore structure and the physical properties of the reservoirs. This study combined NMR, MNRC, and other methods to study the pore structure of tight reservoirs and pointed out that quantitative research methods have good applicability in tight reservoir pore structure and reservoir evaluation. The results obtained can be employed to shape hydrocarbon enrichment regulation and minimize exploration-associated risks.

\section{Materials and Methods}

2.1. Geological Setting. Dongpu Depression, which covers a total area of approximately $5300 \mathrm{~km}^{2}$, is located in the southeastern part of the Bohai Bay Basin of the North China platform (Figure 1). Considering its long-term evolution process, it has undergone several tectonic events [30]. At the end of the Late Proterozoic, North China formed a combined land mass that became a stable platform in the Middle Triassic [31, 32], and with the disintegration of the North China continent after the Yanshan Movement, Dongpu Depression was gradually formed and, thereafter, experienced three important tectonic evolution stages, finally forming a series of faults and four-structure units on the plane $[31,33]$. These faults control the sedimentary thickness and distribution range of the Cenozoic strata. Further, from bottom to top, the strata of the Dongpu Depression are stable epicontinental carbonated deposits of Lower Paleozoic, coal-bearing clastic rock strata of Upper Paleozoic, red sand and mudstone of Middle Permian under arid climate conditions, and river-lake facies gypsum salt-bearing clastic rocks of Cenozoic [33]. A previous study indicated that two sets of petroleum systems, including the Upper Paleozoic and Cenozoic petroleum systems, exist in the Dongpu Depression [34]. Specifically, in the Upper Paleozoic petroleum system, the coal seams of the Upper Paleozoic, which are characterized by a large thickness, a wide distribution range, and a high abundance of organic matter, function as good source rocks [35-37]. Additionally, the medium- and fine-grained sandstone of the Permian Low Shihezi and Shiqianfeng Formations, which are characterized by low porosity and ultralow permeability, are the main reservoirs in this petroleum system [30].

2.2. Materials and Analyses. A total of 12 tight sandstone samples were collected from cores from the Permian Shanxi, Lower Shihezi, and Shiqianfeng Formations in the Dongpu Depression of Bohai Bay Basin. The samples, drilled from homogeneous sections, were cylindrical in shape and were approximately $3-5 \mathrm{~cm}$ long, with a diameter of $2.5 \mathrm{~cm}$. After collection, all the samples were dried for $24 \mathrm{~h}$ at $373.15 \mathrm{~K}$ 


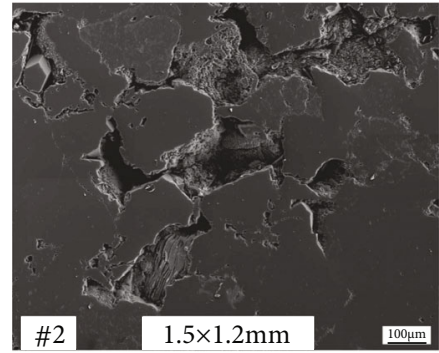

(a)

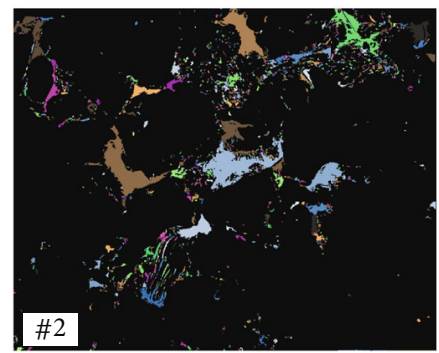

(c)

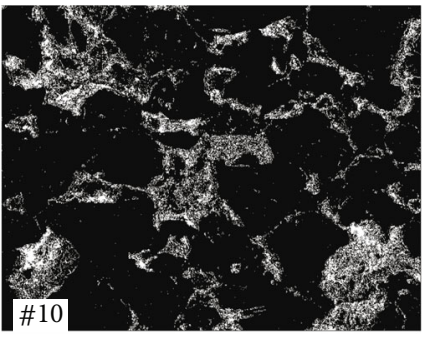

(e)

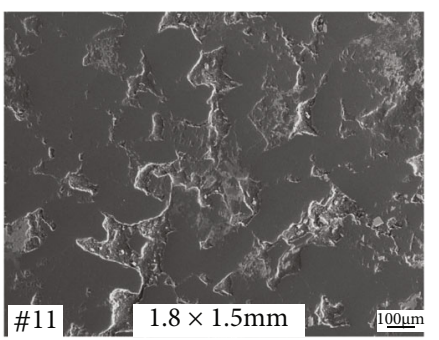

(g)

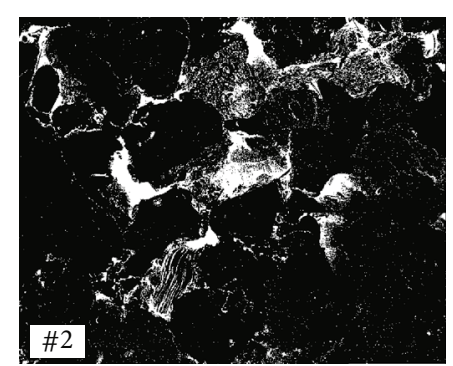

(b)

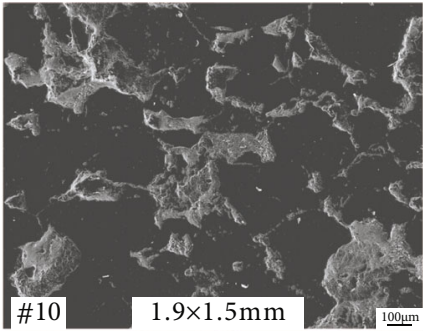

(d)

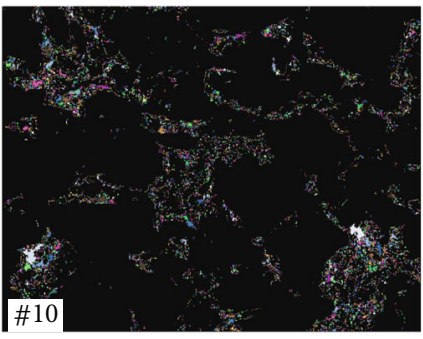

(f)

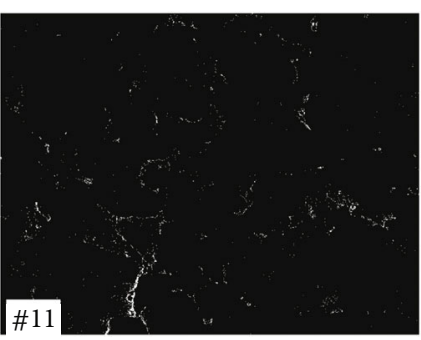

(h)

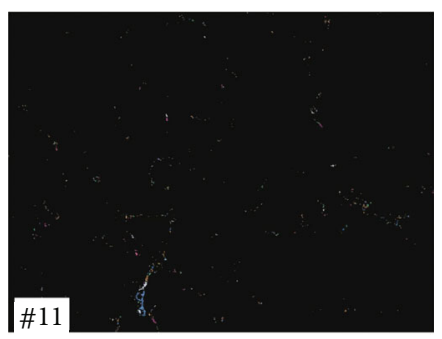

(i)

Figure 4: Flat surface extraction FESEM images of different sample types. (a), (d), and (g) are the original SEM images; (b), (e), and (h) are the PCAS-binarized images; and (c), (f), and (i) are the divided images.

before the test analyses. All the measurements mentioned were performed at the Nanjing University, Nanjing, China.

Firstly, the helium porosity and nitrogen permeability were detected by CMS-300 automatic permeability measur- ing instrument following the standard GB/T 29172-2012. Then, in order to accurately identify the pore types and diagenesis characteristics, casting thin sections (CTS) and subslices were prepared. Casting thin sections were 


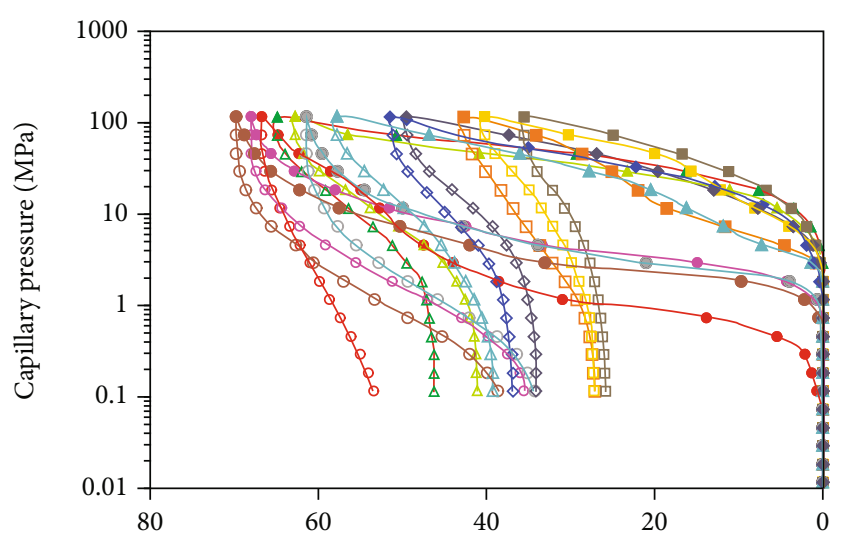

Hg saturation (\%)

$\begin{array}{cccc}\text { Type I } & \text { Type II } & \text { Type III } & \text { Type IV } \\ \rightarrow \# 1 & \rightarrow \# 6 & \rightarrow \# 5 & -\# 11 \\ \rightarrow-\# 2 & \rightarrow \# 10 & \rightarrow \# 8 & -\# 12 \\ \rightarrow-\# 3 & \rightarrow \# 7 & & -\# 9 \\ \rightarrow-\# 4 & & & \end{array}$

FIgURE 5: Mercury intrusion and extrusion curves corresponding to the sandstone samples.

impregnated with blue epoxy and observed by the Axiom Scope $5(\mathrm{Al})$ pol in Key Laboratory of Surficial Geochemistry, Ministry of Education. The subslices were core samples with a volume of $1 \mathrm{~cm} * 1 \mathrm{~cm} * 0.5 \mathrm{~cm}$ and observed by ZEISS Sigma 500 Field Emission Scanning Electron Microscope (FESEM) in Key Laboratory of Surficial Geochemistry, Ministry of Education. To collect high-resolution images of the pore structure, the core samples were firstly polished with sandpaper and then etched with three beams of argon ion (TIB) by Leica EM TIC 3X instrument in National Laboratory of Solid-State Microstructures. The instrument parameters were set to voltage $6.5 \mathrm{kV}$, current $2.5 \mathrm{~mA}$, and the experiment was $3 \mathrm{~h}$.

Following the experiments of TIB and FESEM, the subslices were grounded into 200 mesh for XRD analysis. The XRD analysis is performed on Neo-DMAX IIIa diffractometer in the State Key Laboratory for Mineral Deposits Research, with $\mathrm{Cu} \mathrm{K} \alpha$ radiation, voltage of $37.5 \mathrm{kV}$, beam current of $30 \mathrm{~mA}$, scanning angle from $3^{\circ} \sim 70^{\circ}$, and a step size of $0.02^{\circ}$.

The HPMI experiment was carried out by Autopore IV 9505 porosimetry analyzer. The maximum intrusion pressure is $116.7 \mathrm{MPa}$, corresponding to the pore radius of $6 \mathrm{~nm}$.

NMR and NMRC experiments were both conducted by NMRC pore analyzer $12-010 \mathrm{~V}$, manufactured by Niumag Corporation Ltd., China. In order to realize a favorable signal-to-noise ratio, the test parameters were echo spacing of $0.2 \mathrm{~ms}$, waiting time of $5 \mathrm{~s}$, scanning times of 128 , and echo trains of 2048. Firstly, the mass and bulk volume of samples were measured by electric balance and drainage method, prospectively. After dried at $373.15 \mathrm{~K}$ for $24 \mathrm{~h}$ and vacuumed for $24 \mathrm{~h}$, these samples were put into the NMR instrument for the first-time test. The $\mathrm{T}_{2}$ spectrum of unsaturated water and NMR porosity were obtained. After the first-time test, the samples were fully saturated with deionized water at $20 \mathrm{MPa}$ for $24 \mathrm{~h}$ and the $\mathrm{T}_{2}$ spectrums of saturations were acquired by the second time NMR testing. By processing the twice measurements via software, the transverse relaxation time $\mathrm{T} 2 \mathrm{spec}-$ trum of movable porosity can be obtained.

NMRC is a new method for measuring the nanometer pore of coal and shale and based on the Gibbs-Thomson equation $[28,38,39]$. In recent years, this experiment has also been used for tight sandstone pore size analysis [13, 28]. On the basis of previous experience, we picked the octamethylcyclotetrasiloxane (OMCTS) as the probe liquid for its large $K_{\mathrm{GT}}$ and amphiphilic wetting [13]. The specific experimental procedure was as follows. Firstly, the sample grinded to $20 \sim 35$ mesh and then put it into a $2 \mathrm{ml}$ chromatographic bottle together and vacuumed for $12 \mathrm{~h}$. Then, the probe liquid was injected. The samples were equilibrated and centrifuged for $12 \mathrm{~h}$, so that the probe liquid spontaneously enters the pores of the sample by self-imbibition. Afterwards, the samples were put into the device for measurement. The Carr-Purcel-Meibom-Gill (CPMG) sequence used in the NMRC test sample process in this article. The test parameters were echo spacing of $1 \mathrm{~ms}$, waiting time of $2500 \mathrm{~ms}$, scanning times of 32, and echo trains of 2000 [10]. In the experiment, 28 different temperature points were set to test from 253.15 to $291.15 \mathrm{~K}$. Once the desired temperature was reached, the CPMG measurement would start after 10 minutes. The specific experimental steps were detailed in Figure 2.

\section{Results}

3.1. Bulk Mineralogy. Table 1 shows that the sandstone samples primarily consisted of quartz, feldspar, and clay minerals, followed by small amounts of calcite, siderite, halite, and pyrite. Specifically, the quartz, feldspar, and clay contents of the sandstone samples varied in the ranges $42.5-$ $78.7 \%, 6.1-45.3 \%$, and $1.4-26.8 \%$, respectively. Further, samples 1 and 2 showed high quartz contents, but low feldspar and clay mineral contents, while the other samples (samples 7, 9, 10, and 11) showed high quartz and clay mineral contents, but low feldspar contents. Additionally, sample 8 had a high quartz and feldspar content, while its clay mineral content was relatively low (Table 1).

3.2. Petrophysical Properties and Pore Types. The porosity and permeability of the sandstone samples are presented in Table 2, which shows that the porosity and permeability of the samples varied in the ranges $2.1-8.8 \%$ and $0.0245-$ $0.188 \mathrm{mD}$, respectively. These samples could be classified under four reservoir types based on the differences in their compositions and physical properties: type I reservoirs showed high quartz contents and low clay mineral contents, with their porosity varying in the range $7.21-8.85 \%$; type II reservoirs showed high clay contents, with their porosity ranging between 4.29 and 6.19\%; type III reservoirs, with high quartz contents, and porosity in the range 3.72 and $4.36 \%$; and type IV reservoirs, with high quartz and clay mineral contents and porosity in the range $2.13-3.16 \%$.

Pores do not only serve as essential storage space for hydrocarbons in tight sandstone reservoirs, but also function 


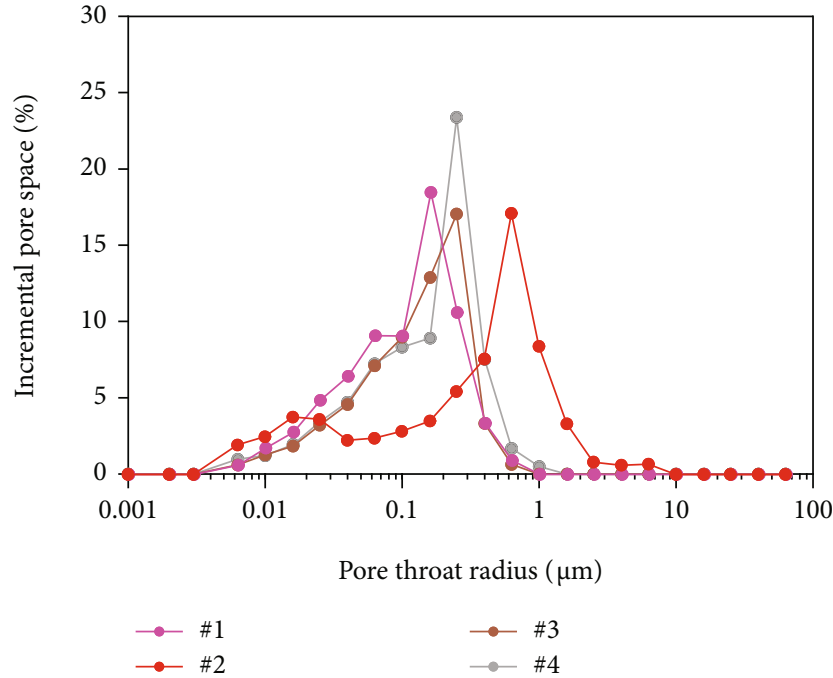

(a)

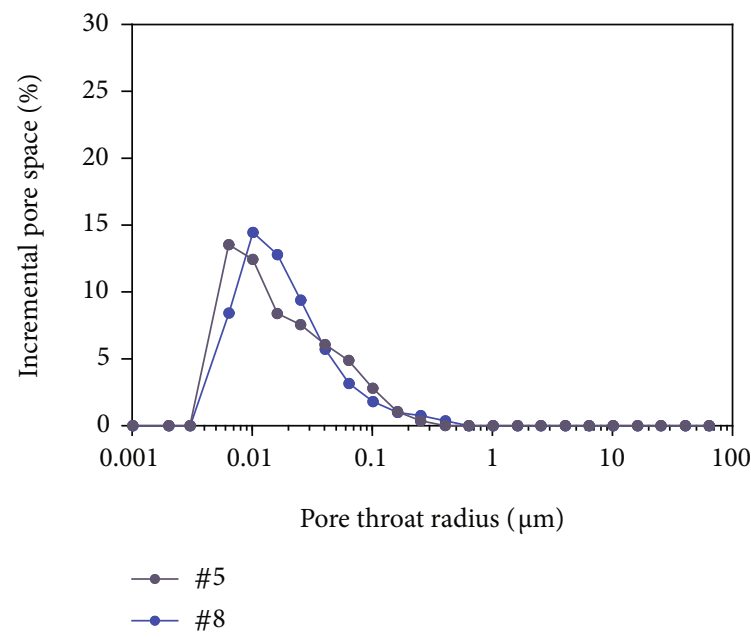

(c)

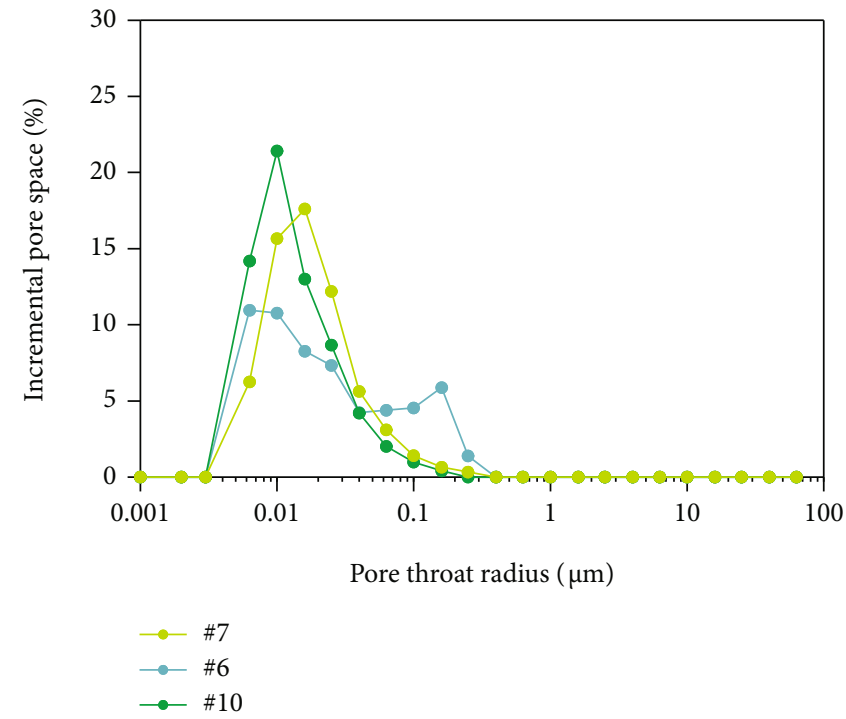

(b)

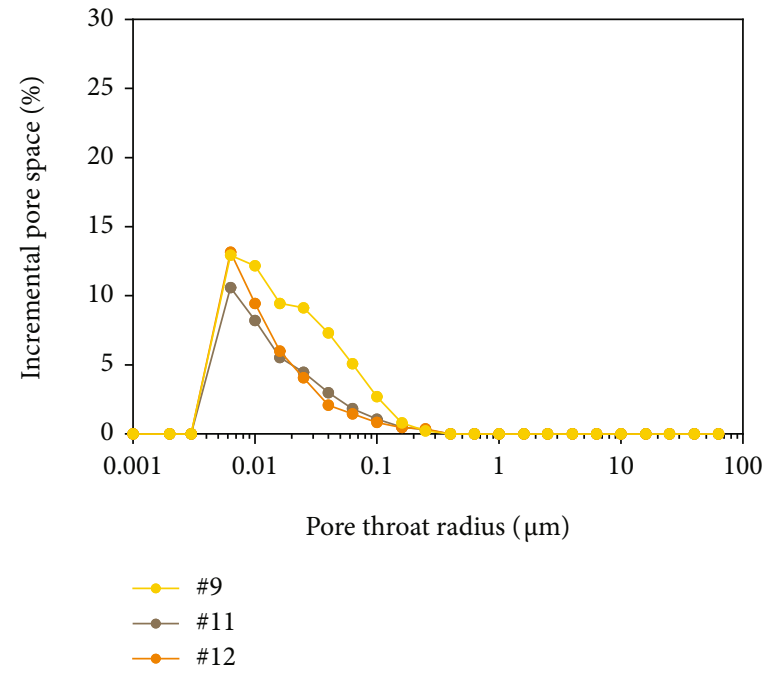

(d)

Figure 6: Pore throat distribution corresponding to the four types of tight sandstone reservoirs.

as critical channels for diagenetic fluids. Therefore, the use of TIB etching coupled with FESEM to observe the surface of tight sandstone samples with a large field of view does not only satisfy the observation requirements for tight sandstones, but also more accurately characterizes the pore structure of the reservoir. Further, with the help of PCAS software, the pore throats in the image were accurately identified, and relevant parameters, including region percentage, average form factor, probability entropy, and fractal dimensions, were automatically extracted [40]. Thus, three pore types, including intergranular, intragranular, and intercrystalline pores, were observed in the tight sandstone samples via SEM imagery (Figure 3). All these pores were secondary dissolved pores rather than primary pores. Furthermore, both intergranular and intragranular pores, which were common in type I and type II reservoirs, resulted from the dissolution of feldspar and lithic frag- ments. The intergranular pores, with irregular shapes and strongly curved edges, appeared comparatively bigger, with their diameters varying in the range $20-400 \mu \mathrm{m}$ (Figures 3(a)-3(c)). Conversely, intragranular pores had relatively small sizes, with their diameters varying in the range 5-100 $\mu \mathrm{m}$ (Figures 3(a), 3(c), and (d)), while intercrystalline pores, which were frequently encountered in type II and IV reservoirs, were characterized by an angular shape and showed much smaller pore sizes. They were also found to be predominantly distributed in clay aggregates, including kaolinite and chlorite (Figures 3(e), 3(h), and 3(i)), followed by carbonate minerals (Figure 3(f)).

Multiple FESEM images corresponding to the same sample were combined to obtain a larger image via a stitching technology. Thereafter, different parameters were extracted using PCAS software. In the process of extracting the parameters, and with reference to helium porosity 


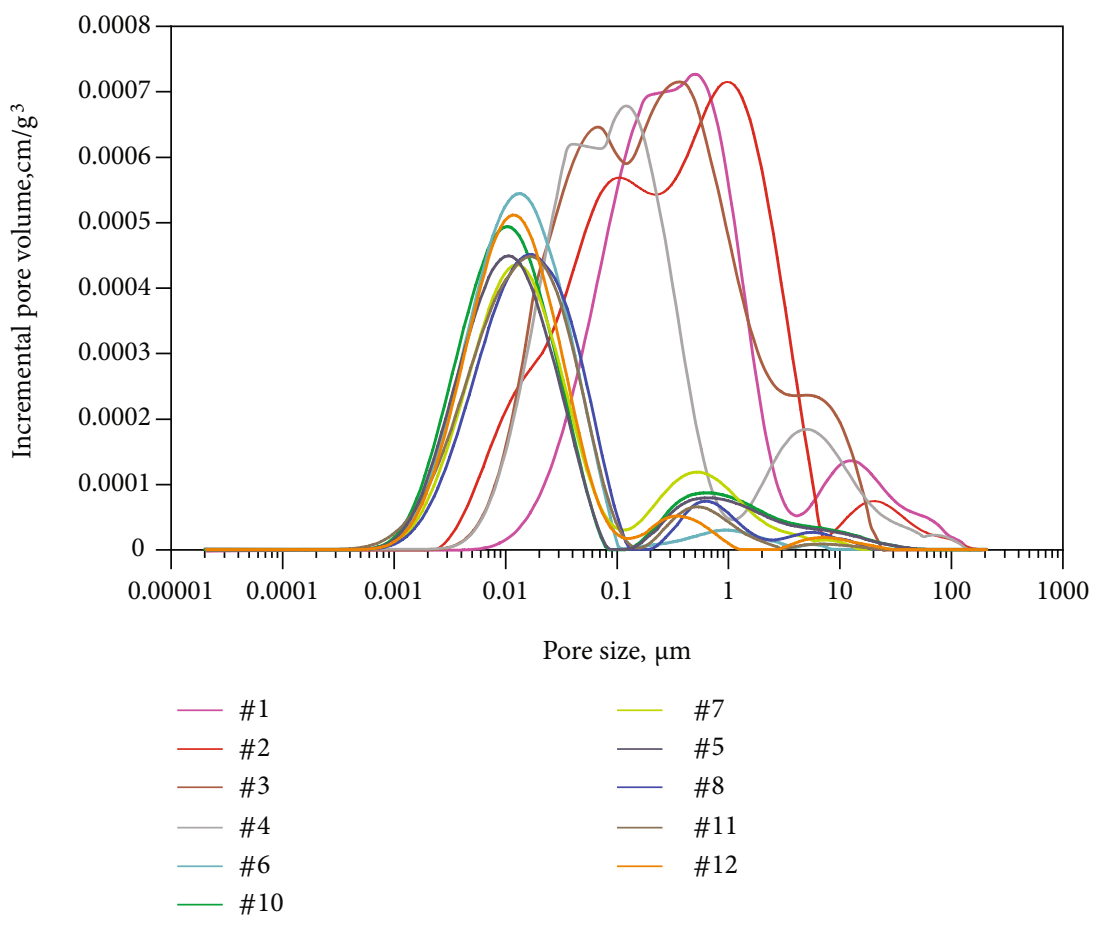

FIGURE 7: NMR-based PSD curves corresponding to four tight sandstone sample types.

data, a unified threshold was selected for the different samples to control the relative error. The high-precision original SEM image and the extracted image of the pore throats are shown in Figure 4. The relevant parameters extracted using PCAS software, including region percentage, pore number, average form factor, and probability entropy, are shown in Table 2. For image area differences, in this study, we stated the number of pores per $1 \mathrm{~mm}^{2}$ of each sample, and it varied from 472 to 4174 . Further, the average form factor $(f f)$ was used to describe the shape of the pores, and the probability entropy $(H)$ was used to characterize the direction of the pores. They were defined as follows:

$$
f f=\frac{4 \pi S}{C^{2}}
$$

where $S$ represents pore area and $C$ represents pore perimeter $[40,41]$. The form factor varied between 0.4662 and 0.6147 , and in general, its value decreased as the complexity of the pore edge increased.

$$
H=-\sum_{i=1}^{n} P_{i} \log _{n} P_{i}
$$

where $P_{i}$ represents the proportion of pores within a specific angle range. In the $2 \mathrm{D}$ plane space, the angle ranged from $0^{\circ}$ to $180^{\circ}$, and the $i$ value varied from 1 to 18 [40]. Further, the probability entropy varied between 0.7384 and 0.9913. Normally, the value of probability entropy increases as the pore arrangement tends to be chaotic.

\subsection{Pore Structure}

3.3.1. HPMI Results. The mercury intrusion and extrusion curves of the tight sandstone samples are shown in Figure 5. The $P_{d}$ of type I reservoirs was less than $1 \mathrm{MPa}$, and their $\mathrm{Hg}$ saturation was over $65 \mathrm{MPa}$. Further, the mercury intrusion increased rapidly within a small invasion pressure range that corresponded to the obvious horizontal stage in the early stage of the mercury intrusion. For type II reservoirs with $1 \mathrm{MPa}<P_{d}<3 \mathrm{MPa}$ and $60 \mathrm{MPa}<S_{\text {Hgmax }}<65 \mathrm{MPa}$, the amount of mercury intrusion basically remained unchanged within the smaller intrusion pressure range, and within the larger intrusion pressure range, as the intrusion pressure increased, the intrusion curve increased steadily. Furthermore, the shape of the intrusion curves of type III and type IV reservoirs was similar to that of type II reservoirs; however, the vertex position of the intrusion curve shifted to the right, and the $P_{d}$ and $S_{H \max }$ values of these two reservoir types increased and decreased, respectively.

Based on the experimental data corresponding to highpressure mercury intrusion, the relationship between the pore throat radius and the differences in mercury saturation was generated, as shown in Figure 6, from which it is evident that type I reservoirs were characterized by a bimodal distribution pattern, with the right peak spanning 0.16 and $1.60 \mu \mathrm{m}$ and with peak values in the range $0.25-1.00 \mu \mathrm{m}$ and the left peak spanning 0.006 and $0.10 \mu \mathrm{m}$ (Figure 6(a)). The other three types of reservoirs were characterized by a left-skewed Gaussian distribution spanning 0.006 and $0.063 \mu \mathrm{m}$; however, the peak values were different 


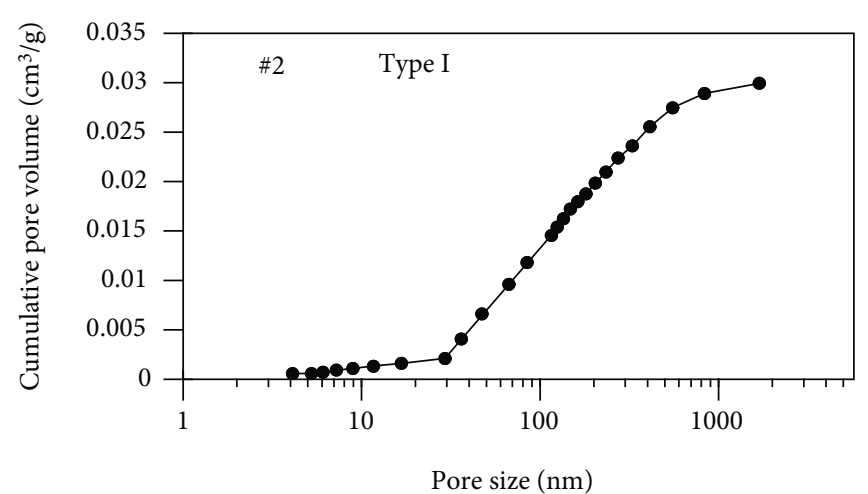

(a)

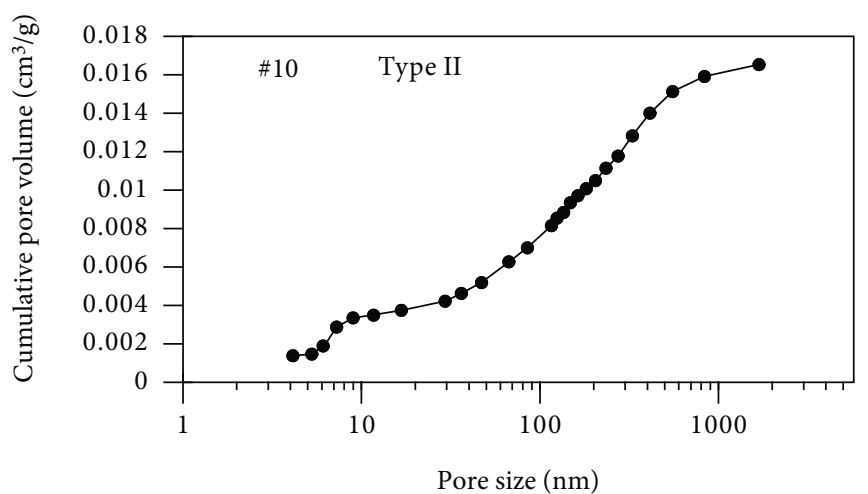

(c)

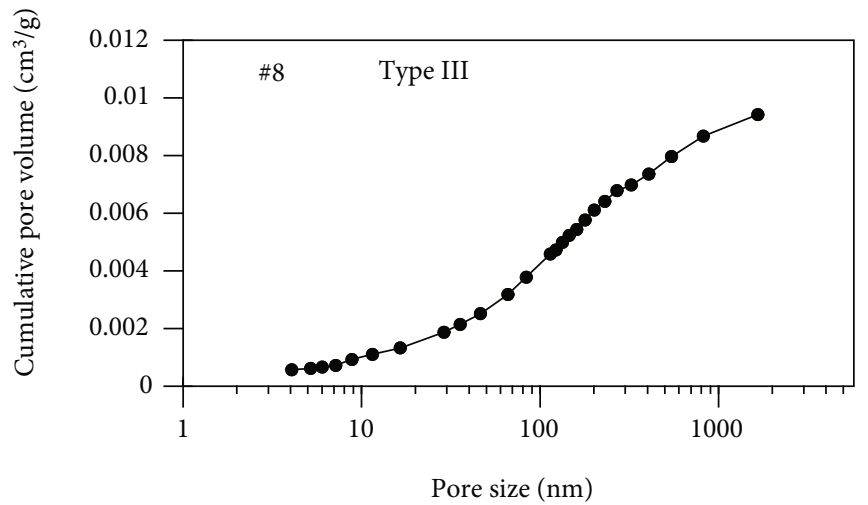

(e)

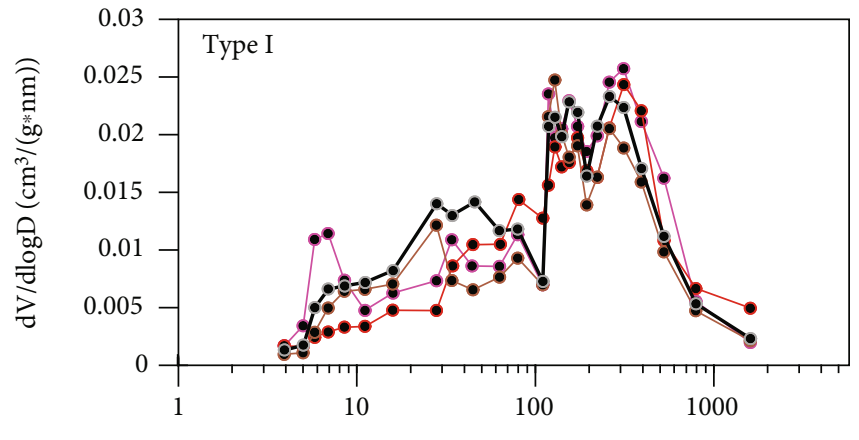

Pore size $(\mathrm{nm})$

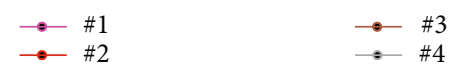

(b)

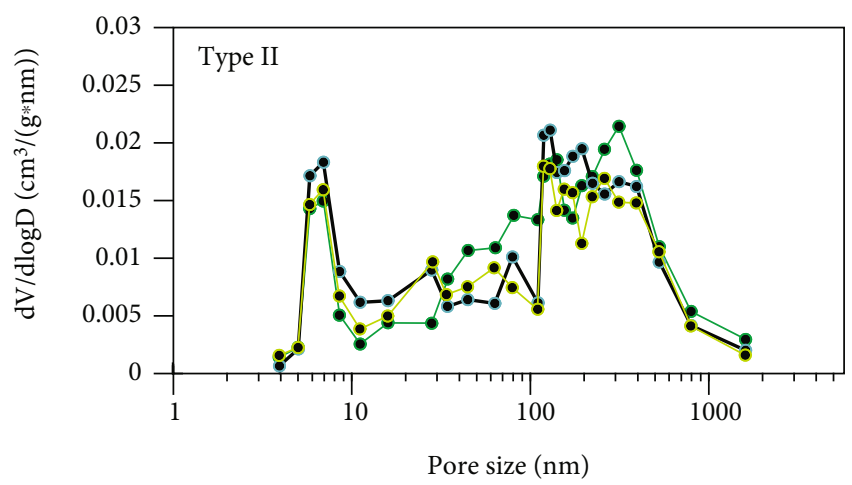

$$
\begin{array}{ll}
- & \# 7 \\
- & \# 6 \\
- & \# 10
\end{array}
$$

(d)

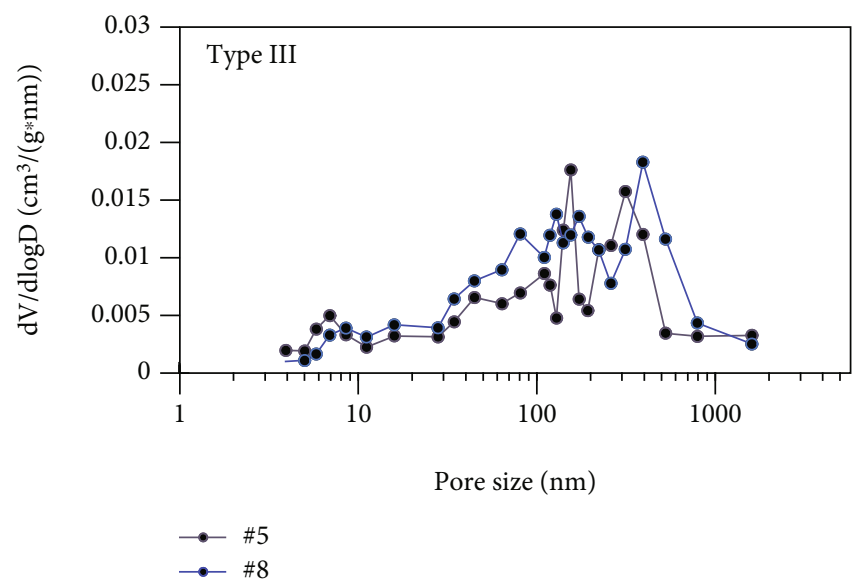

(f)

Figure 8: Continued. 


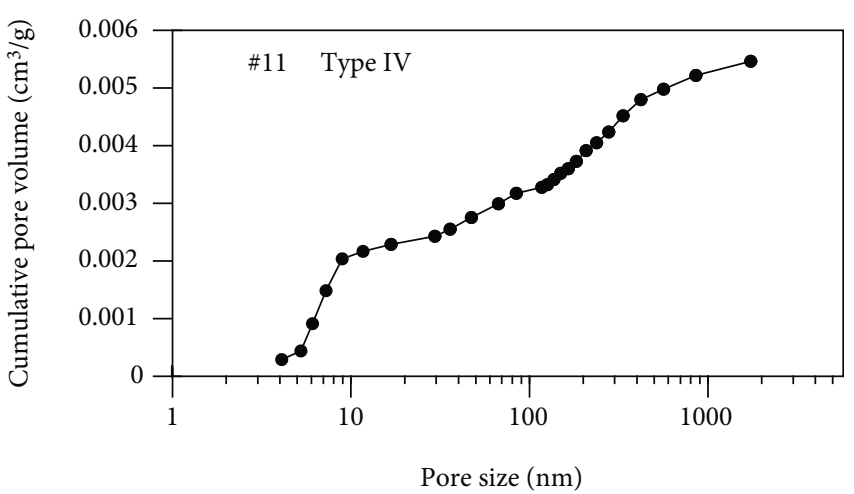

(g)

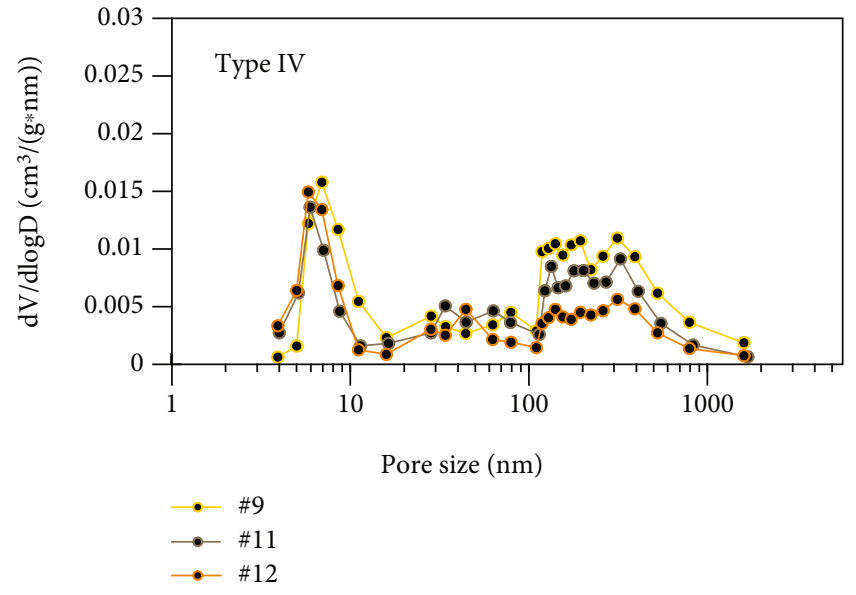

(h)

FIGURE 8: Cumulative pore volume and NMRC-based PSD curves of four types of tight sandstone reservoirs.

(Figures 6(b)-6(d)). Specifically, type II reservoirs had a peak value of $0.016 \mu \mathrm{m}$, and the incremental pore space corresponding to their pore sizes was $17.6 \%$. For type III and IV reservoirs, the peak position was 0.01 and $0.006 \mu \mathrm{m}$, and the incremental pore spaces were 14.5 and $10.6 \%$, respectively.

3.3.2. NMR Results. The volume, connectivity, and PSD of sandstone reservoirs can be reflected by the inversion of NMR $\mathrm{T}_{2}$ results $[19,42,43]$. In general, a long relaxation time corresponds to large pores, while a short relaxation time corresponds to small pores [5]. On the one hand, the PSD curves derived from the NMR of type I reservoirs predominantly ranged from 0.01 to $10 \mu \mathrm{m}$, and the peak value of the pore size varied in the range $0.1-2 \mu \mathrm{m}$ (Figure 7 ). On the other hand, the PSD curves of types II, III, and IV reservoirs all showed a bimodal pattern and the main peaks, which were significantly different from those of type I reservoirs, and shifted to smaller pore sizes, in the range 0.001$0.1 \mu \mathrm{m}$. Except for amplitude, the PSD curves of these other three reservoir types did not show significant differences in pattern, range, and width. Thus, it was difficult to distinguish their pore structure characteristic via the inversion of NMR curves only.

3.3.3. NMRC Results. The cumulative pore volume growth curve and PSD results based on NMRC experiments are shown in Figure 8. The NMRC-based cumulative pore curves revealed that the different types of sandstone reservoirs had different total pore volumes and pore volume change rates. Specifically, type I reservoirs showed the largest total pore volume, and their cumulative pore volume increased slightly and gently at the initial stage. When their pore sizes reached $27.7 \mathrm{~nm}$, their cumulative pore volume showed a steep rise, and thereafter, maintained a significant upward trend (Figure 8(a)). For type II and III reservoirs, the total pore volume declined significantly, while their cumulative pore volumes rose gradually (Figures $8(\mathrm{c})$ and $8(\mathrm{e})$ ). Notably, the cumulative pore volume of type II reservoirs showed a slight increase at a pore size of approximately $9 \mathrm{~nm}$ (Figure 8(c)), and type IV reservoirs showed the lowest total pore volume. The cumulative pore volumes of these reservoirs grew rapidly at the initial stage, and the growth rate slowed down when the pore diameter reached $10 \mathrm{~nm}$ (Figure 8(g)).

Additionally, the PSD patterns of the four types of tight sandstone reservoirs differed significantly. Specifically, type I reservoirs showed a broad continuous unimodal distribution (Figure $8(\mathrm{~b})$ ), with the peak pore size varying in the range $100-500 \mathrm{~nm}$, and with a peak value above $0.025 \mathrm{~cm}^{3} /(\mathrm{g} * \mathrm{~nm})$. Further, the PSD curve of type II reservoirs showed a bimodal pattern, with the peak pore size varying in the ranges 5-10 and $115-350 \mathrm{~nm}$ (Figure $8(\mathrm{~d})$ ), and compared with type I reservoirs, the peak amplitude of type II reservoirs showed a significant decrease. For type III reservoirs, like type I reservoirs, the peak was primarily distributed between 125 and $375 \mathrm{~nm}$; however, the peak amplitude was further attenuated compared with the above two reservoir types (Figure 8(f)). The PSD curve of type IV reservoirs also shows a bimodal characteristic; however, the peak in the range $4-11 \mathrm{~nm}$ was more obvious (Figure $8(\mathrm{~h})$ ). In brief, from type I to type IV reservoirs, the amplitude of the PSD curve showed a gradual decrease in the range $125-500 \mathrm{~nm}$, indicating a decrease in the proportion of macropores. Additionally, the PSD curves of type II and IV reservoirs showed obvious peaks between 4 and $11 \mathrm{~nm}$, suggesting that these two types of reservoirs had higher fine mesopore contents.

3.4. Diagenesis Characteristics. The significant diagenesis included compaction, dissolution, and cementation (e.g., authigenic kaolinite and quartz overgrowth). Feldspar, rock debris, and tuff were identified as primarily responsible for dissolution (Figures 9(a)-9(d)). In type I reservoirs, the dissolution of feldspar and rock debris resulted in the formation of honeycomb or moldic pores (Figures 9(a)-9(c)), while in type II reservoirs, a large amount of authigenic kaolinite appeared like scattered patches and vermicular or booklet-like aggregates between the intergranular dissolution pores, resulting in the blockage of intergranular spaces (Figures 9(d)-9(g)). Nevertheless, most of the authigenic 


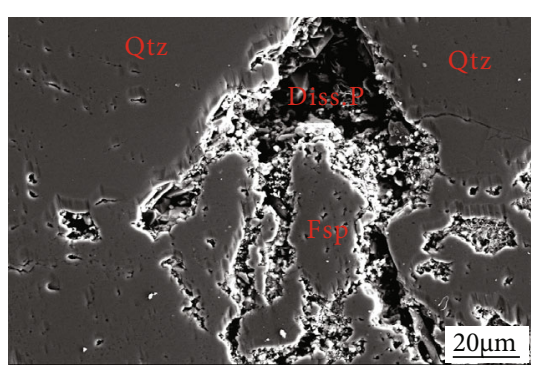

(a)

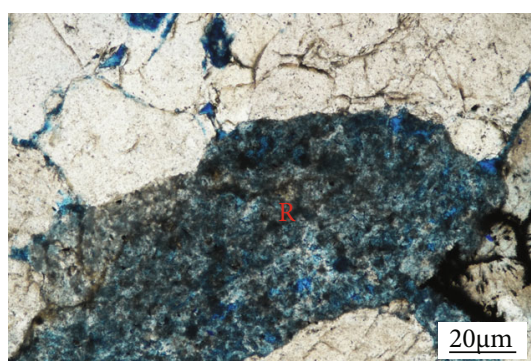

(c)

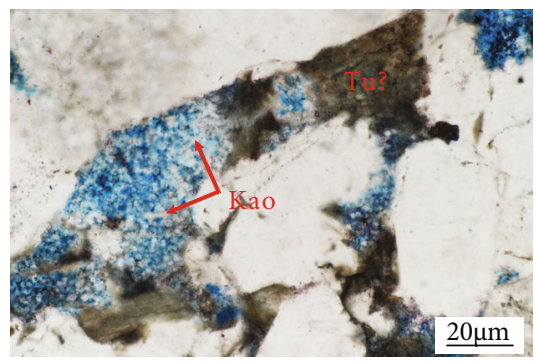

(e)

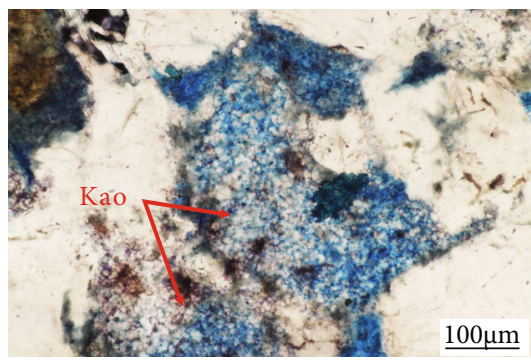

(g)

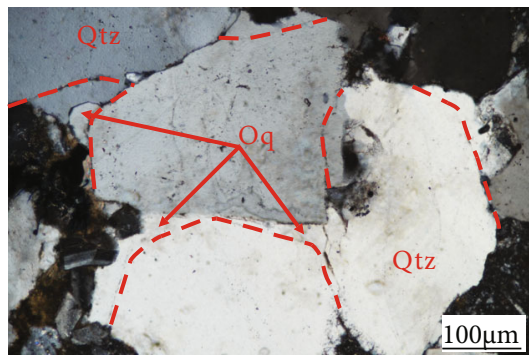

(i)

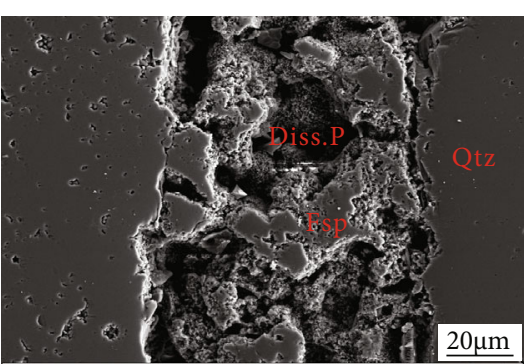

(b)

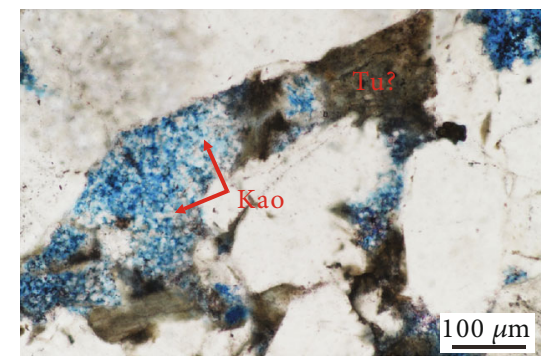

(d)

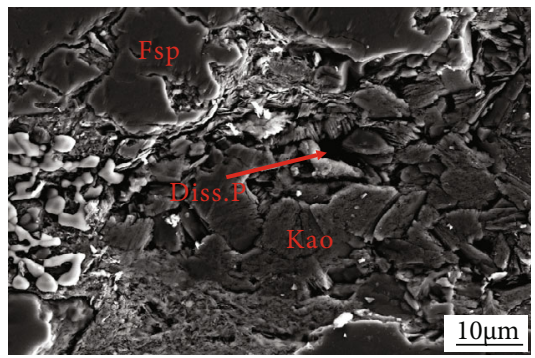

(f)

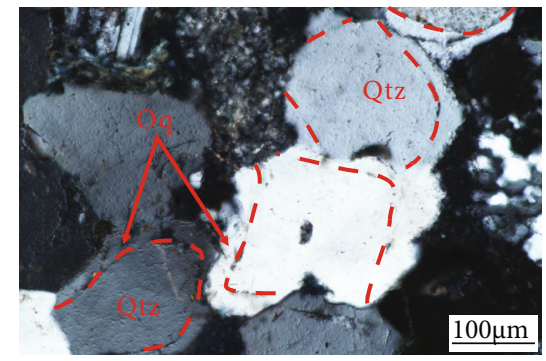

(h)

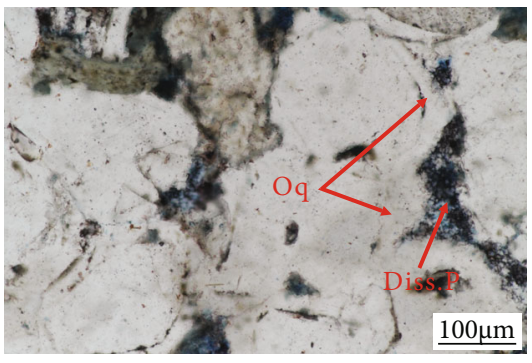

(j)

Figure 9: Continued. 


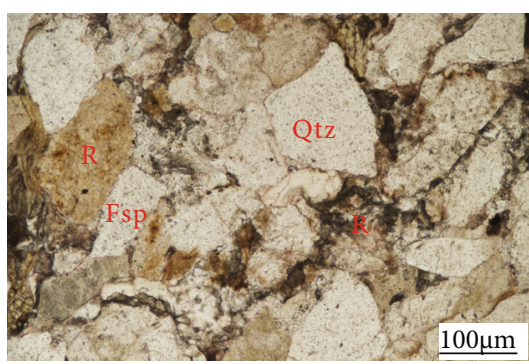

$(\mathrm{k})$

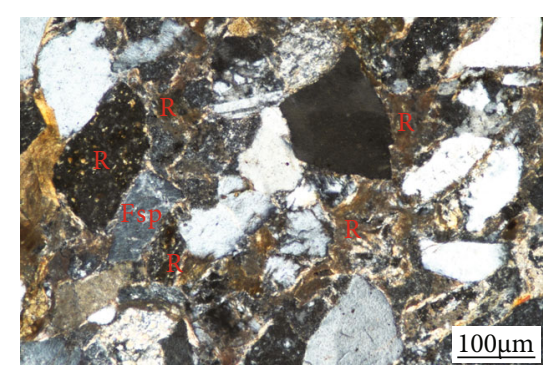

(1)

FIGURE 9: Diagenesis characteristic of tight sandstone samples. (a)-(b) SE2 images of sample \#2. The dissolution of feldspar resulted in the formation of honeycomb pores. (c) Plane-polarized micrograph of sample \#1. The dissolution of rock debris resulted in the formation of moldic pores. (d) Plane-polarized micrograph of sample \#10. Authigenic kaolinite precipitated in the tuff dissolution space. (e) Backscatter image of sample \#7. Authigenic kaolinite remained in intercrystalline voids. (f) SE2 image of sample \#7. Kaolinites were tightly heaped. (g) Plane-polarized micrograph of sample \#10. Authigenic kaolinite remained within intercrystalline voids. (h)-(j) Micrograph of sample \#8. The quartz overgrowth that filled the primary and dissolution pores was easily observable in the matrix-poor samples. (k) Plane-polarized micrograph of sample \#12. The sandstone sample had undergone intense compaction and was characterized by linear, concave, and convex contacts. (l) Crosspolarized micrograph of image A. The ductile fragments were deformed. R: rock debris; Fsp: feldspar; Qtz: quartz; Oq: overgrowth quartz; Diss. p: dissolution pores; Kao: kaolinite.

kaolinite retained some intercrystalline voids, and silica that dissolved from feldspar and rock debris was identified as the main source of quartz overgrowth cementation (Figures $8(\mathrm{~h})-8(\mathrm{j}))$. These quartz overgrowths were more frequently encountered in type III reservoirs, which were rich in quartz and were characterized by a poor matrix. In general, the thickness of quartz overgrowth, which partially or completely filled primary and dissolution pores, varied in the range $10-50 \mu \mathrm{m}$ (Figure 9(j)). Type IV tight sandstone reservoirs were found to be characterized by linear, concave, and convex contacts (Figures $9(\mathrm{k})$ and 9(l)), and the intensity of the mechanical compaction varied with the composition of the sandstone reservoirs. For example, the compaction effects of tight sandstone reservoirs with high contents of ductile fragments were more intense than those of reservoirs with high quartz and feldspar contents.

\section{Discussion}

4.1. Integration of NMR and NMRC to Characterize the FullRange of PSD. The experimental results showed that the tight sandstone reservoirs in Dongpu Depression are characterized by multiple pore types and pore throat size distribution. However, as mentioned before, the application of HPMI, NMR, and MNRC did not offer the possibility to detect the pore throat size distribution of the samples owing to their different limitations. For example, HPMI and NMR curves could reveal the PSD characteristic of type I reservoirs but could not effectively clarify the PSD characteristics of the other three reservoir types (Figures 5 and 7), while the NMRC experiments could display the pore structure and PSD characteristics of the reservoirs and showed obvious differences between the PSD curves of the four types of reservoirs with respect to peak shape and amplitude. Compared with HPMI and NMR, even though the NMRC could accurately characterize the pores in tight sandstone reservoirs in the range $4-1400 \mathrm{~nm}$, it greatly narrowed down the measurement range $[10,28]$. Therefore, it was difficult to use a single experiment to characterize the complete PSD of tight sandstone reservoirs. Furthermore, even though several scholars have attempted to reveal the overall PSD of tight sandstone reservoirs via the integration of multiple techniques and have established a new method of integrating $\mathrm{N}_{2} \mathrm{GA}$ and NMR via points of connection (POC) to the end of realizing the full PSD of tight sandstone reservoirs $[18,25,39]$, the full PSDs obtained using these methods cannot reveal nanoscale pore characteristics owing to the unsuitable nature of the techniques. Therefore, we attempted to integrate NMRC with NMR using the POC technique to the end of effectively deriving the full range PSD of tight sandstone reservoirs.

The first step to conflating PSD based on NMRC and NMR curves is to define the points of connection (POC); the unit incremental volumes of pores are equal at the point when two PSD curves intersect $[18,25]$. Thereafter, choosing the appropriate parts of the PSD curves between the different POCs is crucial. In this study, two POCs in the PSD curves of type I and type II reservoirs were identified. The first junction point, where the two curves overlapped, was $\mathrm{POC}_{1}$, and the last junction was POC 2 (Figure 10(a)). Thus, the full PSDs of type I and type II reservoirs consisted of the following parts: the part on the left of $\mathrm{POC}_{1}$, which was primarily determined via $\mathrm{NMR}$, the part on the right of $\mathrm{POC}_{1}$, but on the left of $\mathrm{POC}_{2}$, which was determined via NMRC, and the part on the right of $\mathrm{POC}_{2}$, which was determined via NMR. For type III and IV reservoirs, we considered choosing the last point of intersection of the two curves as the only POC, so that the results of NMRC could be possibly incorporated into the full PSDs (Figure 10(b)). Thus, the PSD on the left of the POC was determined via NMRC, while that on the right was determined via NMR.

The full range PSDs of the reservoirs are shown in Figure 10, from which it is evident that the PSDs of the tight sandstone reservoirs in the Dongpu Depression have a wide range and show various distribution patterns. For type I reservoirs, with porosity above $6.0 \%$, the overall PSD appeared 


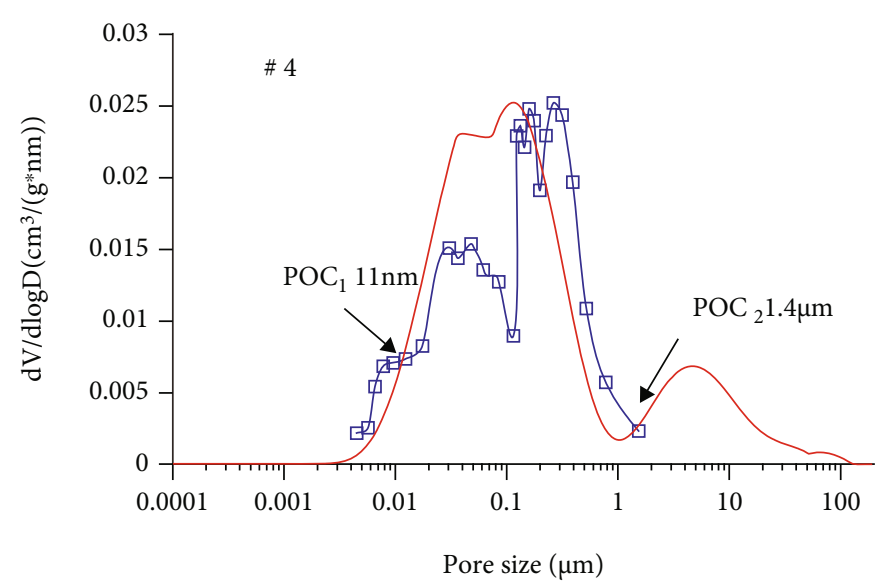

(a)

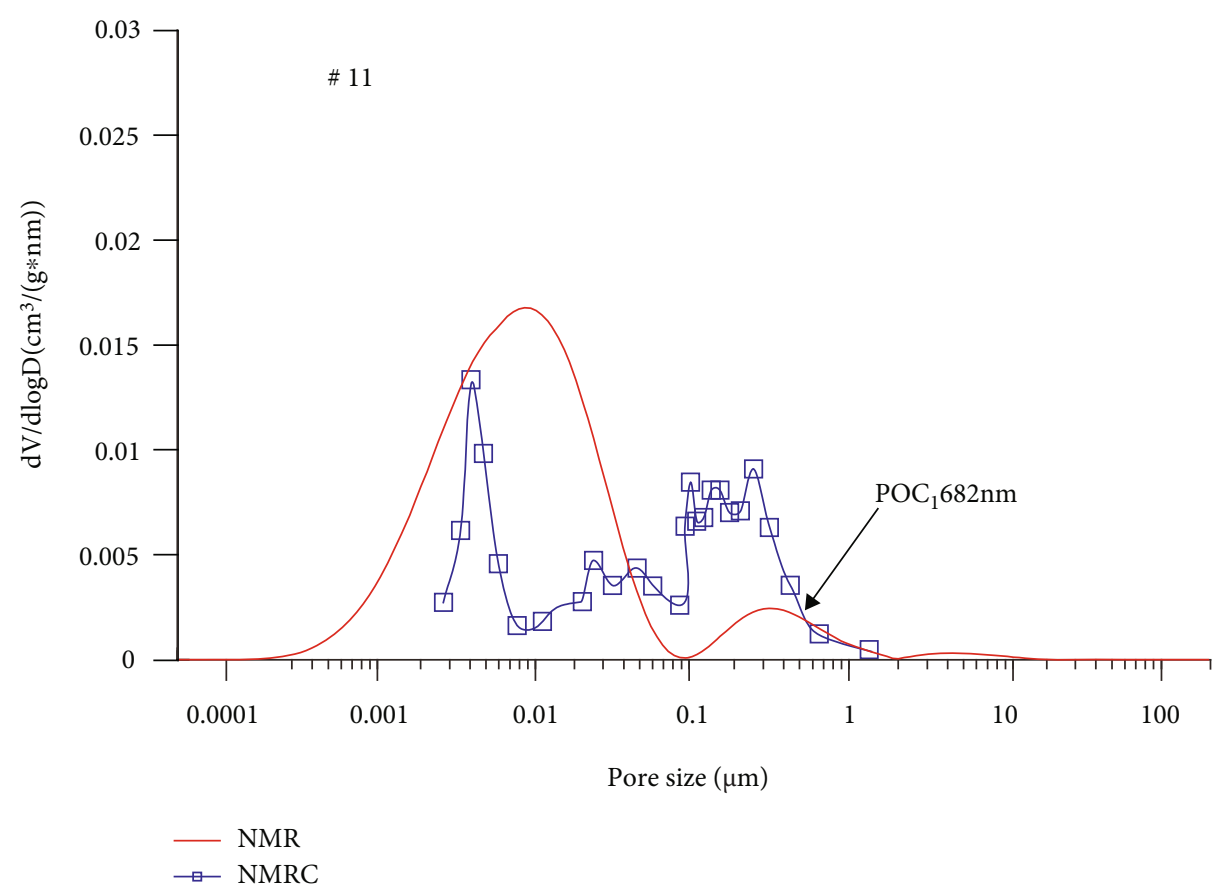

(b)

FIgURe 10: Comparison of PSDs derived from NMR and NMRC and determination of POCs.

right-skewed on the $x$-axis and was characterized by broad unimodal distribution patterns, with the peaks primarily varying in the range $0.1-2 \mu \mathrm{m}$, indicating that macropores were predominant (Figure 11). With the decreasing porosity, the overall PSD was dominated by narrow bimodal distribution patterns, with the peak shifting to the left. Additionally, the right and left peaks varied in the ranges $0.1-0.35 \mu \mathrm{m}$ and $0.004-0.01 \mu \mathrm{m}$, respectively. For type II reservoirs, the left and right peaks showed similar amplitudes, implying the predominance of both mesopores and macropores. Further, the amplitude of the left peak of type IV reservoirs was much higher than that of their right peak, demonstrating that in type IV reservoirs, mesopores are dominant, followed by macropores (Figure 11). Furthermore, the peaks of the PSD curves of type III reservoirs varied in the range 0.05$0.35 \mu \mathrm{m}$; however, their amplitudes showed significant atten- uation, indicating the predominance of macropores; however, their amplitude was attenuated.

4.2. Effect of Pore Structure on Reservoir Quality under the Influence of Different Diagenetic Processes. The complex diagenesis experienced by tight sandstone reservoirs during the long burial process does not only change their original pore system, but also exert a profound control effect on the storage and migration capacity of the pore system [21, 42, 44, 45]. Previous studies have demonstrated that diagenesis can change the number of pore spaces and the distribution range of pore throats, as well as their connectivity [46-50]. Additionally, it has also been demonstrated that compaction, the dissolution of framework particles, and clay mineral content are the main factors that control the pore volume of sandstone reservoirs $[12,51,52]$. Therefore, after 


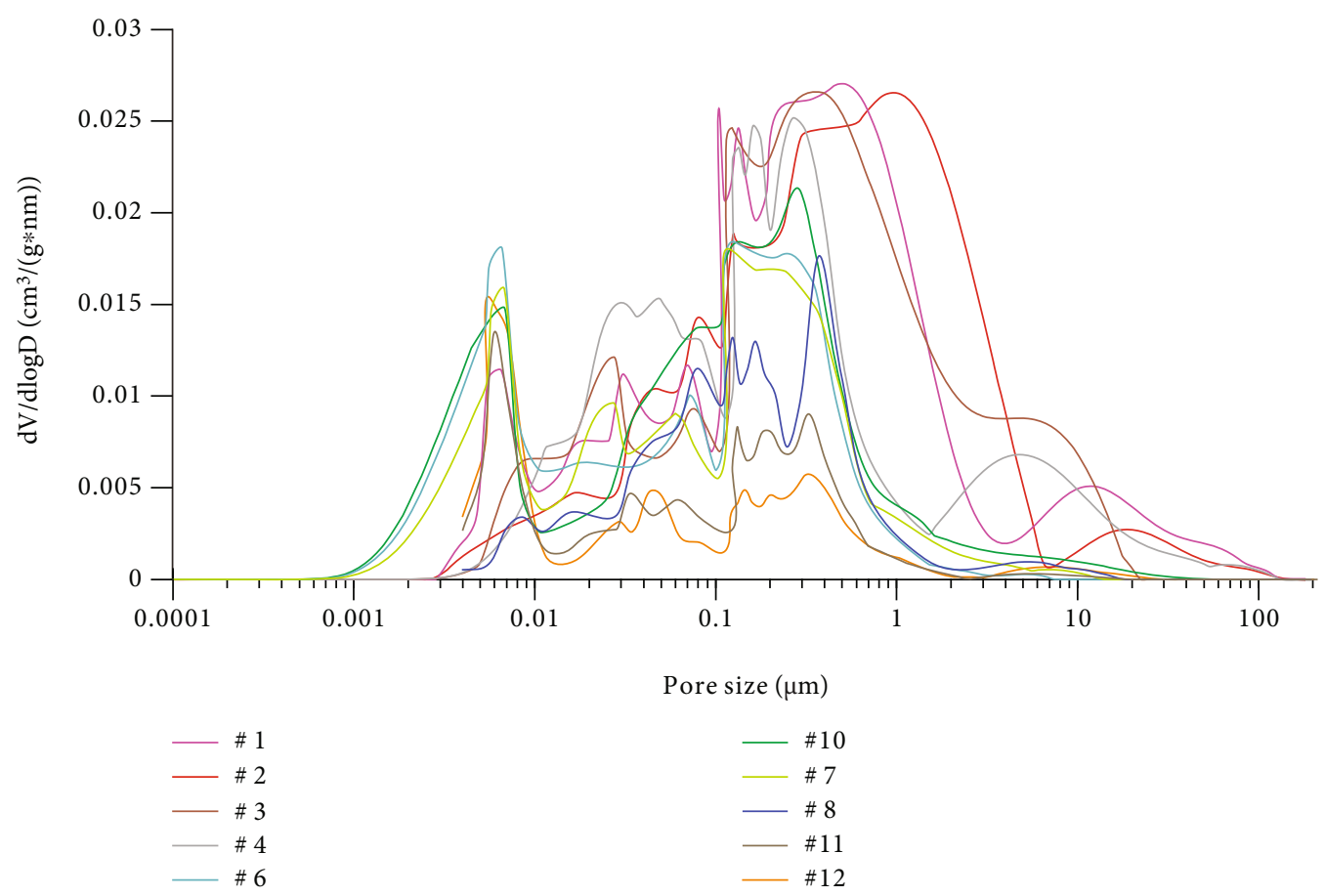

FIGURE 11: Overall pore size distribution based on the integration of NMRC and NMR curves.

understanding the full PSD of the reservoirs, coupled with their microscopic characteristics, the characteristics of different types of pore structures and their influence on the quality of the reservoir under different diagenetic influence could be determined.

Petrographically, it was observed that dissolved feldspar formed oversized intergranular pores in type I reservoirs (Figures 3(a), 9(i), and 9(j)). Moreover, further observations from multiple perspectives showed that except for dissolution, there was no nearby precipitation of quartz overgrowth, carbonate cement, or clay minerals in these reservoirs. Additionally, from a mineralogical perspective, type I reservoirs had a low clay mineral content, while their framework particle content was high. Therefore, following the water-rock interaction that occurred in type I reservoirs, large volumes of solids were transported away owing to diffusion; thus, dissolution-enlarged intergranular and intragranular pores were formed easily [53]. The pore structure characteristics of intergranular and intragranular pores with large pore sizes are shown as the peaks ranging from $100 \mathrm{~nm}$ to $2 \mu \mathrm{m}$. For type II reservoirs, after the dissolution of feldspar and tuff, aluminum and some silicon precipitated in situ or nearby as kaolinite (Figures 3(e) and 9(f)-9(h)). This pore-filling kaolinite played a significant role in reducing pore apertures as well as pore volume [42]. Nevertheless, it was still possible to observe some intergranular dissolution pores that had not yet been filled (Figure 3(c)). Therefore, the bimodal pattern of NMR-based PSD curves showed a mixed pore structure composed of mesopores (intercrystalline pores) and macropores (intergranular pores) (Figure 11). Type III reservoirs showed quartz overgrowths around detrital quartz that resulted in a significant decrease in pore volume (Figures 9(c)-9(e)). However, the fluid not only caused silica to precipitate but also resulted in the dissolution of framework grains to form a few intergranular pores. Thus, the full PSD curves of type III reservoirs showed one peak between 125 and $375 \mathrm{~nm}$. However, the amplitude of this peak was attenuated, implying that the pore volume and number, especially those of macropores, had reduced (Figure 11). Finally, it was evident that type IV reservoirs, with high clay mineral contents, had undergone intense mechanic compaction, resulting in pore loss and the prevention of the entrance of fluids; thus, the pore structures were dominated by intercrystalline pores. Therefore, the PSD curves of type IV reservoirs showed a more obvious peak in the $4-11 \mathrm{~nm}$ range (Figure $8(\mathrm{~h})$ ).

In summary, the PSD curves not only reflected differences in pore structures but also indicated the different contributions of the pores to the total porosity (pore volume) under different pore sizes, i.e., different pore structures had different effects on reservoir quality. Therefore, based on the results of the NMRC experiments, the pore volume contribution ratios of the four types of reservoirs in the ranges 4-11 nm $\left(R_{E}\right)$ and $180-375 \mathrm{~nm}\left(R_{A}\right)$ were separately calculated. The $R_{E}$ and $R_{A}$ values showed correlation with total porosity. Specifically, $R_{E}$ values showed negative correlation with porosity (Figure 12(a)), while $R_{A}$ values showed positive correlation (Figure 12(b)), indicating that in reservoirs with high porosity, the contribution of large pores to porosity was predominant, while that of small pores was insignificant. This implies that micropore-dominated pore structures have a more significant effect on the capacity of reservoirs, such as type I and type II reservoirs. Conversely, the samples with high clay mineral contents showed 


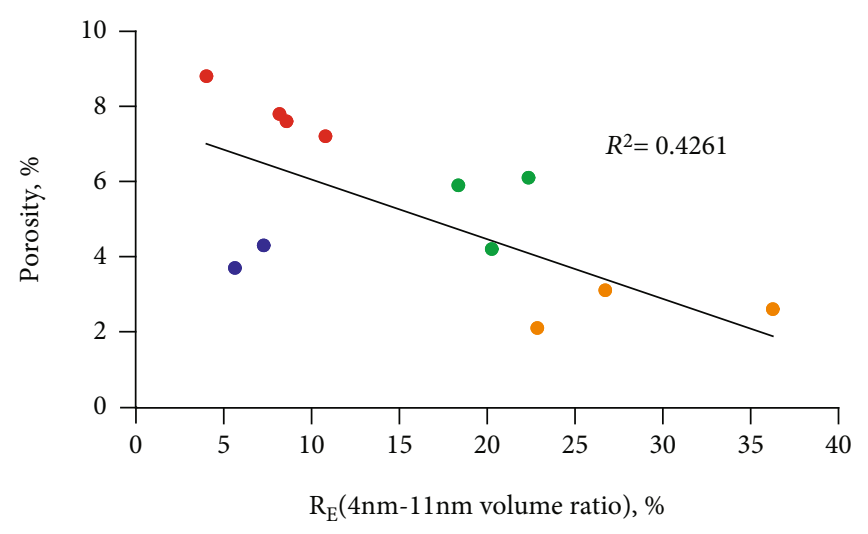

(a)

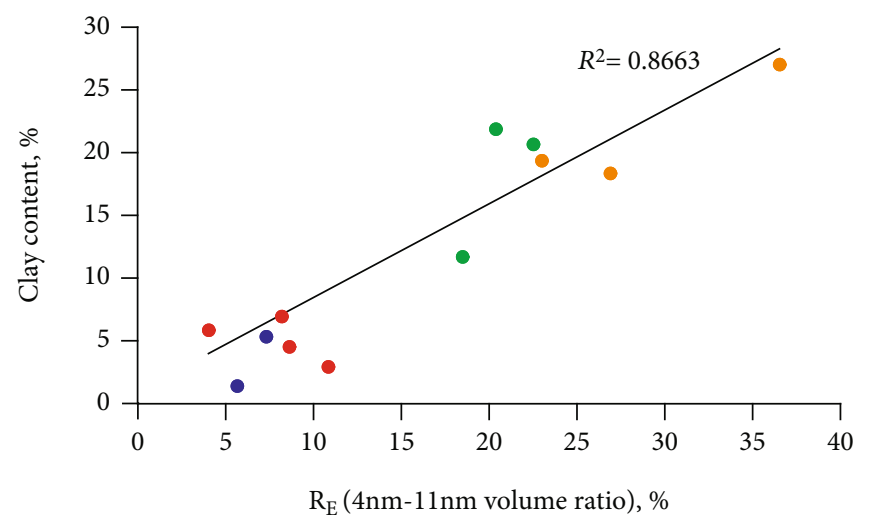

(c)

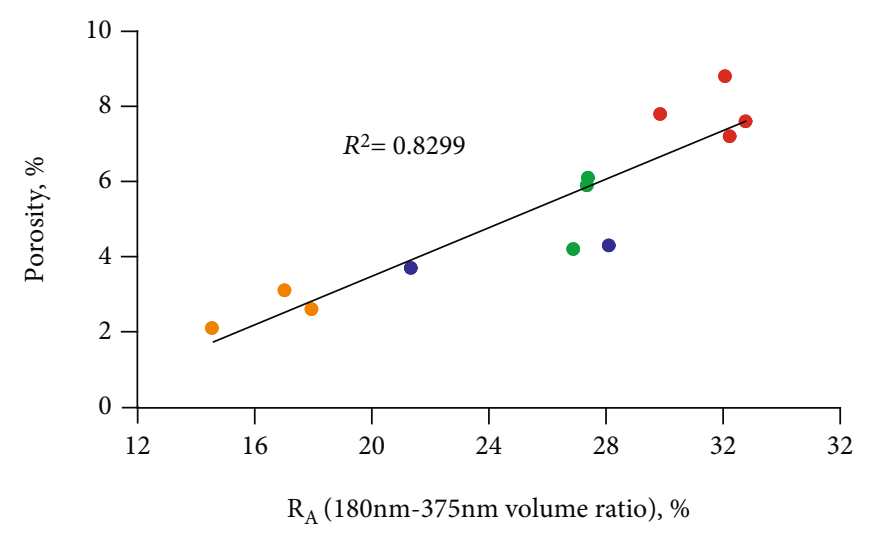

(b)

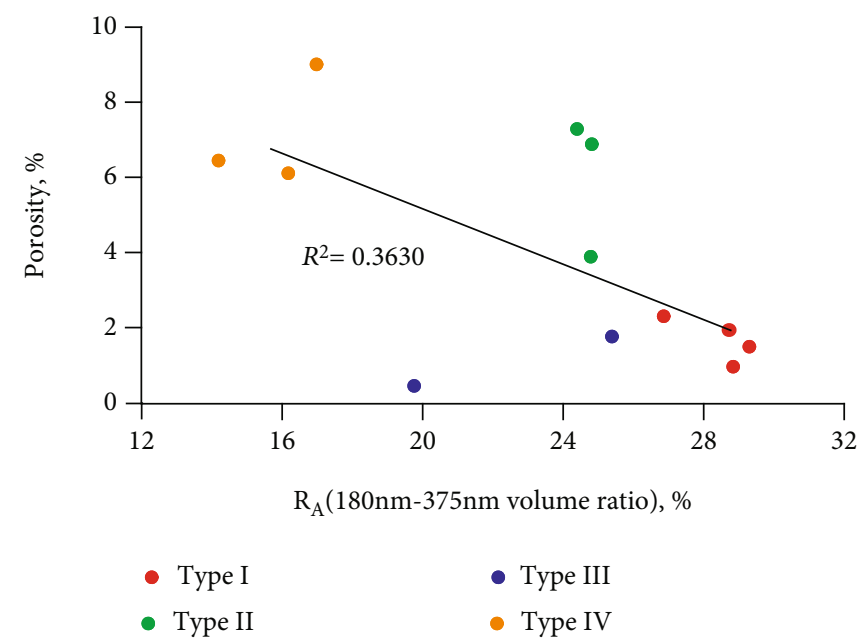

(d)

Figure 12: (a, b) Relationships between porosity and pore volume proportion. (c, d) Relationships between clay content and pore volume proportion.

relatively high $R_{E}$ values (Figure $12(\mathrm{c})$ ), but had low $R_{A}$ values (Figure 12(d)). One explanation for this observation is that intercrystalline pores are predominantly distributed in the clay mineral. Thus, an increase in clay mineral content would lead to an increase in the number of intercrystalline pores. Besides, the dissolution of aluminum silicate minerals and tuff would lead to the generation of secondary clay minerals, resulting in an increase in number of mesopores and a decrease in the number of macropores. It was also observed that reservoirs with mesopore-dominated pore structures were characterized by poor storage properties.

4.3. Evolution of Different Pore Structures. The physical properties, pore structure characteristics (shape factor and probability entropy), thin sections, NMR curves, HPIM curves, and NMRC curves of the four reservoir types identified in this study are summarized and compared (as shown in Figure 13).

Type I reservoirs showed the best macroscopic property. Based on thin section analysis, their pore structure consisted of intergranular and intragranular pores formed as a result of dissolution. The primary pores were lost owing to compaction during the burial process; however, the dissolution of feldspar particles resulted in the formation of a large number of micron-scale dissolved pore. This type of reservoir showed a low shape factor and a high probability entropy, implying that it has a relatively smooth pore edge and an orderly pore arrangement, with large effective pore areas [54]. The HPMI curve of this reservoir was characterized by a low threshold pressure and showed the highest relative maximum mercury saturation $\left(S_{H_{\text {gmax }}}\right)$ at approximately $70 \%$, indicating that the pores of type I reservoirs in the Upper Paleozoic of Dongpu Depression show the best connectivity. Additionally, the PSD curves were characterized by unimodal and right-skewed patterns along the $x$-axis, implying the predominance of intergranular macropores.

Additionally, the pore structures of type II reservoirs consisted of both intragranular mesopores and intergranular macropores owing to the dissolution of framework grain and tuff as well as Kaolinite filling. Further, compared with type I reservoirs, the most significant feature of type II reservoirs 


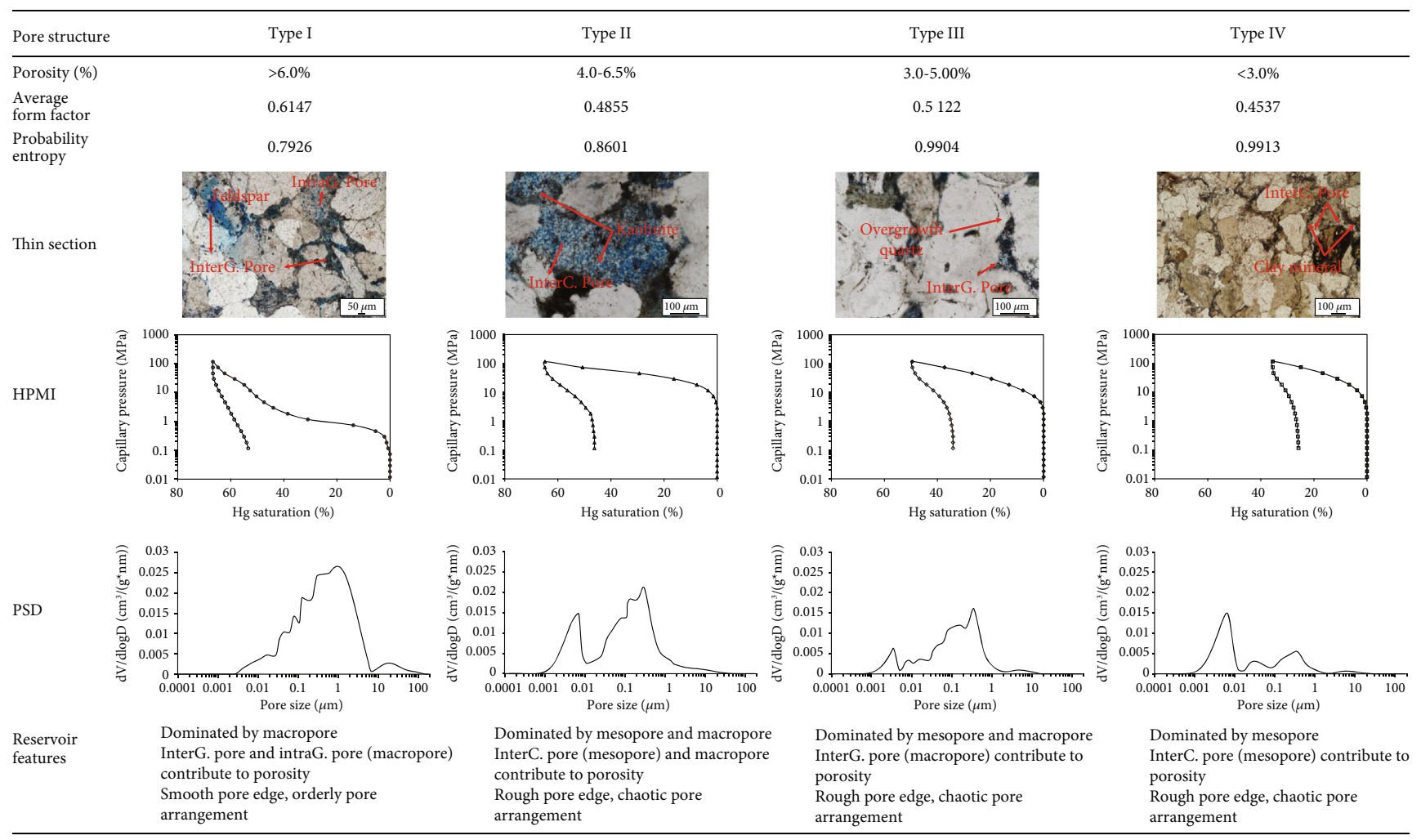

FIGURE 13: Pore structure and physical property of the four reservoir types.

was that a larger amount of authigenic kaolinite was precipitated in the dissolved pores resulting in pore blockage. Furthermore, type II reservoirs had a relative high shape factor and a lower probability entropy compared with type I reservoirs, indicating that they are characterized by a ragged pore edge and a chaotic pore arrangement. The HPMI curve corresponding to type II reservoirs showed a higher threshold pressure as well as a high $S_{H \text { gmax }}$, implying that the pores were heterogeneously distributed, but had good connectivity. The PSD of type II reservoirs also showed a bimodal pattern, which also indicated the coexistence of intergranular pores and kaolinite intragranular pores.

Both type III and IV reservoirs showed poor physical properties. The results of thin section analysis showed that only a few intergranular pores were present in type III reservoirs, while no obvious pores were observed in type IV reservoirs. However, SEM analysis showed the presence of some clay mineral-based mesopores, including chlorite (Figures 3(h) and 3(i)). Additionally, these reservoirs had experienced very intense compaction and cementation, resulting in a significant loss of pores, and similar to type II reservoirs, they were also characterized by ragged pore edges as well as a chaotic pore arrangement. The HPMI curves of type III and IV reservoirs also showed a high threshold pressure and an extremely low $S_{\text {Hgmax }}$, below $40 \%$, indicating that $60 \%$ of the pores were not effectively connected, and the reservoirs had poor connectivity. The amplitudes of their PSD curves were much lower than those of type I and type II reservoirs (Figure 13). Further, even though the PSD curves of type III and IV reservoirs were characterized by a unimodal pattern, some differences existed between them. The peaks corresponding to type III reservoirs varied in the range $0.05-0.5 \mu \mathrm{m}$, indicating the preponderance of intergranular dissolution pores, while that of type IV reservoirs varied in the range $0.002-0.01 \mu \mathrm{m}$, indicating the predominance of clay mineral intercrystalline pores.

\section{Conclusions}

In this study, thin section, XRD, SEM, TIB-PCAS, HPMI, NMR, and NMRC analyses were conducted to determine the pore structure of tight sandstone reservoirs in the Upper Paleozoic of Dongpu Depression. The main conclusions were as follows:

(1) The tight sandstones reservoirs in the Upper Paleozoic of Dongpu Depression consist of diverse fractal pores, including intergranular pores, intragranular pores, and intercrystalline pores, were identified by thin section and SEM images

(2) The integration of NMR and NMRC served as a reliable strategy by which the overall PSD of tight sandstone reservoirs with different pore structures can be described. The studied tight sandstone reservoirs, with a wide pore size distribution, ranging from $4 \mathrm{~nm}$ to $100 \mu \mathrm{m}$, are characterized by unimodal and bimodal patterns. With a decrease in porosity, the pore size at the main peak of the overall PSD curves 
became smaller, with the amplitude showing attenuation

(3) The combination of NMRC and SEM can accurately determine the causes of different pore structures. It was not only a reliable bridge between diagenesis and pore structures but also provided new ideas for evaluation of reservoir quality. The pore structure characteristics of intergranular and intragranular pores with large pore diameters, formed as a result of dissolution, were found to be more beneficial to the formation of high-quality reservoirs

(4) Comprehensive evaluation of the microscopic and macroscopic characteristics of the pore structure of the four types of reservoirs through multiple methods and multiple parameters. Type I reservoirs had a relatively smooth pore edge and an orderly pore arrangement. They also showed the best macroscopic property. Conversely, the other three types of reservoirs were found to be characterized by ragged pore edges and chaotic pore arrangements

\section{Data Availability}

The experimental data used to support the findings of this study are included in the manuscript.

\section{Conflicts of Interest}

The authors declared that they have no conflicts of interest to this work.

\section{Acknowledgments}

This work was financially supported by the National Science and Technology Major Projects of China (Grant no. 2016ZX05006-004).

\section{References}

[1] C. N. Zou, G. S. Zhang, Z. Yang et al., "Concepts, characteristics, potential and technology of unconventional hydrocarbons: on unconventional petroleum geology," Petroleum Exploration and Development, vol. 40, no. 4, pp. 413-428, 2013.

[2] Y. Li, J. H. Yang, Z. J. Pan, S. Z. Meng, K. Wang, and X. L. Niu, "Unconventional natural gas accumulations in stacked deposits: a discussion of upper paleozoic coal-bearing strata in the east margin of the Ordos Basin, China," Acta Geologica Sinica (English Edition), vol. 93, no. 1, pp. 111-129, 2019.

[3] X. M. Zhu, R. Pan, S. F. Zhu, W. Wei, and L. Ye, "Research progress and core issues in tight reservoir exploration," Earth Science Frontiers, vol. 25, no. 2, pp. 141-146, 2018.

[4] D. S. Xiao, S. Jiang, D. Thul, W. B. Huang, Z. Y. Lu, and S. F. $\mathrm{Lu}$, "Combining rate-controlled porosimetry and NMR to probe full-range pore throat structures and their evolution features in tight sands: a case study in the Songliao Basin, China," Marine and Petroleum Geology, vol. 83, pp. 111-123, 2017.

[5] J. C. Qiao, J. H. Zeng, S. Jiang et al., "Insights into the pore structure and implications for fluid flow capacity of tight gas sandstone: a case study in the upper paleozoic of the Ordos Basin," Marine and Petroleum Geology, vol. 118, p. 104439, 2020.

[6] Y. Li, J. H. Yang, Z. J. Pan, and W. S. Tong, "Nanoscale pore structure and mechanical property analysis of coal: an insight combining AFM and SEM images," Fuel, vol. 260, p. 116352, 2020.

[7] Y. Li, Z. S. Wang, Z. J. Pan, X. L. Niu, Y. Yu, and S. Z. Meng, "Pore structure and its fractal dimensions of transitional shale: a cross-section from east margin of the Ordos Basin, China," Fuel, vol. 241, pp. 417-431, 2019.

[8] P. H. Nelson, "Pore-throat sizes in sandstones, tight sandstones, and shales," AAPG Bulletin, vol. 93, no. 3, pp. 329-340, 2009.

[9] S. H. Du, S. Pang, and Y. M. Shi, "A new and more precise experiment method for characterizing the mineralogical heterogeneity of unconventional hydrocarbon reservoirs," Fuel, vol. 232, no. 15, pp. 666-671, 2018.

[10] Z. Yang, C. N. Zou, S. K. Wu et al., "Characteristics of nanosized pore-throat in unconventional tight reservoir rocks and its scientific value," Journal of Shenzhen university science and engineering, vol. 32, no. 3, pp. 257-265, 2015.

[11] B. Bai, R. K. Zhu, S. T. Wu, J. W. Cui, L. Su, and T. T. Li, "New micro-throat structural characterization techniques for unconventional tight hydrocarbon reservoir," China Petroleum Exploration, vol. 19, no. 3, pp. 78-86, 2014.

[12] B. S. Nabawy, Y. Géraud, P. Rochette, and N. Bur, "Pore-throat characterization in highly porous and permeable sandstones," AAPG Bulletin, vol. 93, no. 6, pp. 719-739, 2009.

[13] B. Liu, S. P. Yao, W. X. Hu, and J. Cao, “Applying octamethylcyclotetrasiloxane as a probe liquid for characterizing the pore size distribution of oil-bearing tight sandstones by nuclear magnetic resonance cryoporometry," Marine and Petroleum Geology, vol. 88, pp. 814-825, 2017.

[14] T. T. Yin, D. M. Liu, Y. D. Cai, Y. Zhou, and Y. B. Yao, "Size distribution and fractal characteristics of coal pores through nuclear magnetic resonance cryoporometry," Energy \& Fuels, vol. 31, no. 8, pp. 7746-7757, 2017.

[15] Y. B. Yao, D. M. Liu, Y. Che, D. Z. Tang, S. H. Tang, and W. H. Huang, "Petrophysical characterization of coals by low-field nuclear magnetic resonance (NMR)," Fuel, vol. 89, no. 7, pp. 1371-1380, 2010.

[16] R. Rezaee, A. Saeedi, and B. Clennell, "Tight gas sands permeability estimation from mercury injection capillary pressure and nuclear magnetic resonance data," Journal of Petroleum Science and Engineering, vol. 88-89, pp. 92-99, 2012.

[17] J. Lai and G. W. Wang, "Fractal analysis of tight gas sandstones using high-pressure mercury intrusion techniques," Journal of Natural Gas Science and Engineering, vol. 24, pp. 185-196, 2015.

[18] L. C. Zhang, S. F. Lu, D. S. Xiao, and B. Li, "Pore structure characteristics of tight sandstones in the northern Songliao Basin, China," Marine and Petroleum Geology, vol. 88, pp. 170-180, 2017.

[19] Q. Lei, L. H. Zhang, H. M. Tang, Y. L. Zhao, M. Chen, and C. Y. Xie, "Describing the full pore size distribution of tight sandstone and analyzing the impact of clay type on pore size distribution," Geofluids, vol. 3, 20 pages, 2020.

[20] X. F. Liu, J. F. Wang, L. Ge et al., "Pore-scale characterization of tight sandstone in Yanchang Formation Ordos Basin China using micro-CT and SEM imaging from $\mathrm{nm}$ - to $\mathrm{cm}$-scale," Fuel, vol. 209, no. 1, pp. 254-264, 2017. 
[21] M. Wang, H. M. Tang, H. X. Tang et al., "Impact of differential densification on the pore structure of tight gas sandstone: evidence from the Permian Shihezi and Shanxi formations, eastern Sulige gas field, Ordos Basin, China," Geofluids, vol. 2019, 25 pages, 2019.

[22] J. J. Li, J. X. Yin, Y. N. Zhang et al., “A comparison of experimental methods for describing shale pore features - a case study in the Bohai Bay Basin of eastern China," International Journal of Coal Geology, vol. 152, pp. 39-49, 2015.

[23] Z. Cao, G. D. Liu, H. B. Zhan et al., "Pore structure characterization of Chang-7 tight sandstone using MICP combined with $\mathrm{N}_{2}$ GA techniques and its geological control factors," Scientific Reports, vol. 6, no. 1, p. 36919, 2016.

[24] H. Wu, Y. L. Ji, R. Liu, C. L. Zhang, and S. Chen, "Insight into the pore structure of tight gas sandstones: a case study in the Ordos Basin, NW China," Energy \& Fuels, vol. 31, no. 12, pp. 13159-13178, 2017.

[25] J. C. Qiao, J. H. Zeng, S. Jiang et al., "Role of pore structure in the percolation and storage capacities of deeply buried sandstone reservoirs: a case study of the Junggar Basin, China," Marine and Petroleum Geology, vol. 113, pp. 104129-104129, 2020.

[26] F. J. Dong, X. F. Lu, Y. Cao, X. J. Rao, and Z. Y. Sun, “Microscale pore throat differentiation and its influence on the distribution of movable fluid in tight sandstone reservoirs," Geofluids, vol. 2021, 7 pages, 2021.

[27] J. B. W. Webber, R. Anderson, J. H. Strange, and B. Tohidi, "Clathrate formation and dissociation in vapor/water/ice/hydrate systems in SBA-15, sol-gel and CPG porous media, as probed by NMR relaxation, novel protocol NMR cryoporometry, neutron scattering and ab initio quantum-mechanical molecular dynamics simulation," Magnetic. Resonance. Imaging, vol. 25, no. 4, pp. 533-536, 2007.

[28] F. Zhu, W. X. Hu, J. Cao, B. Liu, Y. F. Liu, and C. Chang, "Probe material choice for nuclear magnetic resonance cryoporometry (NMRC) measurements of the nano-scale pore size distribution of unconventional reservoirs," Energy Exploration \& Exploitation, vol. 37, no. 1, pp. 412-428, 2019.

[29] J. B. W. Webber, "Studies of nano-structured liquids in confined geometries and at surfaces," Spectrosc Progress in nuclear magnetic resonance spectroscopy, vol. 56, no. 1, pp. 78-93, 2010.

[30] P. J. Ma, C. Y. Lin, S. Q. Zhang et al., "Diagenetic history and reservoir quality of tight sandstones: a case study from Shiqianfeng sandstones in upper Permian of Dongpu Depression, Bohai Bay Basin, eastern China," Marine and Petroleum Geology, vol. 89, pp. 280-299, 2018.

[31] H. Su, L. P. Qu, J. C. Zhang et al., "The reservoir forming condition and enrichment rule of the natural gas in the Dongpu Depression, the Bohaiwan Basin," Petroleum Geology and Experiment, vol. 28, no. 2, pp. 70-77, 2006.

[32] L. Liu and Z. Ren, “Thermal evolution of Dongpu Sag," Petroleum Geology and Experiment, vol. 34, no. 4, pp. 419-423, 2007.

[33] H. J. Hu, Y. L. Jiang, J. D. Liu, X. S. Mu, and K. Zhao, "Gas generation evolution and potential analysis of CarboniferousPermian coal-measured source rocks in Dongpu Depression," Earth Science, vol. 43, no. 2, pp. 610-621, 2018.

[34] Y. L. Jiang, L. Fang, Y. M. Tan, and X. S. Mu, "Differences and main controlling factors of accumulation periods in Dongpu Sag, Bohai Bay Basin," Geological Review, vol. 61, no. 6, pp. 1321-1331, 2015.
[35] Z. Q. Hu, X. K. Zhou, and J. H. Zhu, "Hydrocarbon generation potential of Upper Paleozoic in eastern part of North China," Petroleum Geology and Experiment, vol. 33, no. 6, pp. 698701, 2006.

[36] Y. M. Zhu, X. H. Wang, C. Zhang, W. Yuan, C. Cai, and S. B. Chen, "Hydrocarbon-generation evolution of the PermaCarboniferous coal measure in Dongpu Depression," Acta Petrolei Sinica, vol. 28, no. 6, pp. 27-31, 2007.

[37] H. A. Zhang, S. Zhang, Y. X. Zhang, and S. P. Yao, "Simulation of hydrocarbon generation of the Paleozoic coals in the Dongpu Sag, Bohai Bay Basin," Petroleum Geology and Experiment, vol. 39, no. 4, pp. 527-534, 2017.

[38] B. Zhou, Q. Han, and P. Q. Yang, "Characterization of nanoporous systems in gas shales by low field NMR cryoporometry," Energy \& Fuels, vol. 30, no. 11, pp. 9122-9131, 2016.

[39] Y. X. Zhao, Y. F. Sun, S. M. Liu, K. Wang, and Y. D. Jiang, "Pore structure characterization of coal by NMR cryoporometry," Fuel, vol. 190, pp. 359-369, 2017.

[40] C. Liu, B. Shi, J. Zhou, and C. S. Tang, "Quantification and characterization of microporosity by image processing, geometric measurement and statistical methods: application on SEM images of clay materials," Applied Clay Science, vol. 54, no. 1, pp. 97-106, 2011.

[41] G. I. Sezer, K. Ramyar, B. Karasu, A. B. Goktepe, and A. Sezer, "Image analysis of sulfate attack on hardened cement paste," Materials and Design, vol. 29, no. 1, pp. 224-231, 2008.

[42] J. Lai, G. Wang, Z. Wang et al., "A review on pore structure characterization in tight sandstones," Earth Science Reviews, vol. 177, pp. 436-457, 2018.

[43] H. Daigle and A. Johnson, "Combining mercury intrusion and nuclear magnetic resonance measurements using percolation theory," Transport Porous Media, vol. 111, pp. 669679, 2016.

[44] S. Morad, K. Al-Ramadan, J. M. Ketzer, and L. F. DeRos, “The impact of diagenesis on the heterogeneity of sandstone reservoirs: a review of the role of depositional facies and sequence stratigraphy," AAPG Bulletin., vol. 94, no. 8, pp. 1267-1309, 2010.

[45] A. Chagneau, F. Claret, F. Enzmann et al., "Mineral precipitation-induced porosity reduction and its effect on transport parameters in diffusion-controlled porous media," Geochemical Transactions, vol. 16, no. 1, 2015.

[46] S. Sadhukhan, T. Dutta, and S. Tarafdar, "Simulation of diagenesis and permeability variation in two-dimensional rock structure," Geophysical Journal International., vol. 169, no. 3, pp. 1366-1375, 2007.

[47] J. E. Cook, L. B. Goodwin, and D. F. Boutt, "Systematic diagenetic changes in the grainscale morphology and permeability of a quartz-cemented quartz arenite," AAPG Bulletin., vol. 95, no. 6, pp. 1067-1088, 2011.

[48] B. S. Nabawy and C. David, "X-ray CT scanning imaging for the Nubia sandstone as a tool for characterizing its capillary properties," Geosciences Journal, vol. 20, no. 5, pp. 691-704, 2016.

[49] P. S. Mozley, J. E. Heath, T. A. Dewers, and S. J. Bauer, "Origin and heterogeneity of pore sizes in the Mount Simon sandstone and Eau Claire formation: implications for multiphase fluid flow," Geosphere, vol. 12, no. 4, pp. 1341-1361, 2016.

[50] K. E. Higgs, M. J. Arnot, and S. Brindle, "Advances in grainsize, mineral, and pore-scale characterization of lithic and clay-rich reservoirs," AAPG Bulletin., vol. 99, no. 7, pp. 1315-1348, 2015. 
[51] S. Emmanuel, L. M. Anovitz, and R. J. Day-Stirrat, "Effects of coupled chemo-mechanical processes on the evolution of pore-size distributions in geological media," Reviews in Mineralogy and Geochemistry, vol. 80, no. 1, pp. 45-60, 2015.

[52] A. Putnis and G. Mauthe, "The effect of pore size on cementation in porous rocks," Geofluids, vol. 1, no. 1, 2001.

[53] K. Bjørlykke and J. Jahren, "Open or closed geochemical systems during diagenesis in sedimentary basins: constraints on mass transfer during diagenesis and the prediction of porosity in sandstone and carbonate reservoirs," AAPG Bulletin, vol. 96, no. 12, pp. 2193-2214, 2012.

[54] P. Soroushian and M. Elzafraney, "Morphological operations, planar mathematical formulations, and stereological interpretations for automated image analysis of concrete microstructure," Cement \& Concrete. Composites, vol. 27, no. 7-8, pp. 823-833, 2005. 